\title{
Effects of heat and drought on carbon and water dynamics in a regenerating semi-arid pine forest: a combined experimental and modeling approach
}

\author{
N. K. Ruehr ${ }^{1}$, B. E. Law ${ }^{2}$, D. Quandt ${ }^{2}$, and M. Williams ${ }^{3}$ \\ ${ }^{1}$ Karlsruhe Institute of Technology, Institute of Meteorology and Climatology - Institute of Atmospheric Environmental \\ Research, 82467 Garmisch-Partenkirchen, Germany \\ ${ }^{2}$ Oregon State University, College of Forestry, Department of Forest Ecosystems and Society, Corvallis, OR 97331, USA \\ ${ }^{3}$ University of Edinburgh, School of GeoSciences, Edinburgh EH9 3JN, UK
}

Correspondence to: N. K. Ruehr (nadine.ruehr@kit.edu)

Received: 9 December 2013 - Published in Biogeosciences Discuss.: 9 January 2014

Revised: 24 April 2014 - Accepted: 17 June 2014 - Published: 6 August 2014

\begin{abstract}
Predicting the net effects on the carbon and water balance of semi-arid forests under future conditions depends on ecosystem processes responding to changes in soil and atmospheric drought. Here we apply a combination of field observations and soil-plant-atmosphere modeling (SPA) to study carbon and water dynamics in a regenerating ponderosa pine forest. The effects of soil and atmospheric drought were quantified based on a field irrigation experiment combined with model simulations. To assess future effects of intensifying drought on ecosystem processes, the SPA model was run using temperature and precipitation scenarios for 2040 and 2080.

Experimentally increased summer water availability clearly affected tree hydraulics and enhanced $\mathrm{C}$ uptake in both the observations and the model. Simulation results showed that irrigation was sufficient to eliminate soil water limitation and maintaining transpiration rates, but gross primary productivity (GPP) continued to decrease. Observations of stomatal conductance indicated a dominant role of vapor pressure deficit (VPD) in limiting $\mathrm{C}$ uptake. This was confirmed by running the simulation under reduced atmospheric drought (VPD of $1 \mathrm{kPa}$ ), which largely maintained GPP rates at pre-drought conditions.
\end{abstract}

The importance of VPD as a dominant driver was underlined by simulations of extreme summer conditions. We found GPP to be affected more by summer temperatures and VPD as predicted for $2080(-17 \%)$ than by reductions in summer precipitation $(-9 \%)$. Because heterotrophic res- piration responded less to heat $(-1 \%)$ than to reductions in precipitation $(-10 \%)$, net ecosystem $\mathrm{C}$ uptake declined strongest under hotter $(-38 \%)$ compared to drier summer conditions $(-8 \%)$.

Considering warming trends across all seasons (September-May: $+3{ }^{\circ} \mathrm{C}$ and June-August: $+4.5^{\circ} \mathrm{C}$ ), the negative drought effects were largely compensated by an earlier initiation of favorable growing conditions and bud break, enhancing early season GPP and needle biomass. An adverse effect, triggered by changes in early season allocation patterns, was the decline of wood and root biomass. This imbalance may increase water stress over the long term to a threshold at which ponderosa pine may not survive, and highlights the need for an integrated process understanding of the combined effects of trends and extremes.

\section{Introduction}

Drought events are characterized by a continuous decline of soil water content (soil drought) and an increase in evaporative demand (atmospheric drought). The intensity of ecosystem water stress depends therefore largely on the initial soil water status, the length of the drought period and air temperature. The severity of summer droughts is increasing in the northwest US (Easterling et al., 2007; Schwalm et al., 2012), due to higher temperatures and a likely reduction in summer precipitation (Mote et al., 2013). However, our 
ability to predict future effects on forest ecosystems is limited by uncertainty regarding the relative roles of evaporative demand/temperature and precipitation in triggering drought stress (Williams et al., 2013), and by understanding their corresponding effects on component processes like photosynthesis and heterotrophic respiration (Ruehr et al., 2012). For example, gross primary productivity is generally found to decrease more than respiration during drought conditions (Schwalm et al., 2009; Ruehr et al., 2012), because photosynthesis is limited by both soil drought and high temperatures, while soil moisture constraints on heterotrophic respiration may be partially compensated by temperature (Irvine et al., 2008; Ruehr et al., 2012).

Model predictions of drought impacts on the $\mathrm{C}$ cycle of forest ecosystems are further challenged by differences in site conditions that influence the intensity of stress experienced by the ecosystem (e.g., Wright et al., 2013). Moreover, tree adaptation strategies can affect the relative physiological sensitivity to evaporative demand and soil water availability. For example, isohydric pine close stomata early during water stress when vapor pressure deficit is large (MartinezVilalta et al., 2004) to avoid xylem cavitation (McDowell et al., 2008). In contrast, anisohydric juniper are less sensitive and can allow leaf water potentials to decline strongly while stomata remain open to continue photosynthesis (McDowell et al., 2008). Because of a plethora of abiotic and biotic factors involved in buffering and/or facilitating water stress, detailed site and species specific studies on drought stress are necessary to identify thresholds and increase process understanding.

Ponderosa pine (Pinus ponderosa Dougl. ex Laws.) represents a major forest type in semi-arid and Mediterranean climate zones in the northwest US. The abundance of young, planted or naturally regenerating pine forests may increase, due to harvest and stand-replacing fires (Hudiburg et al., 2013; Pierce et al., 2004). However, young forest stands are more susceptible to water stress (Hanson and Weltzin, 2000; Irvine et al., 2004) due to shallower rooting (Williams et al., 2001) and a high vulnerability of the hydraulic system (Domec et al., 2004). Thus, the sensitivity of young ponderosa pine trees to increasingly extreme summer conditions may be considered as a bottleneck in estimating the future distribution and productivity of this forest type.

Detailed process and site specific models can be used to test the sensitivity of component ecosystem fluxes and pools to changes in precipitation and temperature. Such a model of the soil-plant-atmosphere continuum has been developed by Williams et al. (1996). The SPA model estimates carbon and water fluxes at fine temporal scales within the limits of the hydraulic system and includes a detailed multilayer soil and canopy model. The model's drought routine has been extensively tested in a variety of ecosystems worldwide (e.g., Williams et al., 2001; Fisher et al., 2007; Zeppel et al., 2008; Wright et al., 2013). Stomatal conductance is linked to the Farquahr model of leaf-level photosynthesis and the Penman-Monteith equation of leaf-level transpiration to optimize carbon gain per unit leaf nitrogen within the limitations of the hydraulic system. Maximum soil-to-canopy water transport is defined by the difference between soil water potential and the minimum sustainable leaf water potential, and by the hydraulic resistance of the soil-root-leaf pathway. The risk of cavitation is then limited by stomata adjusting to equalize evaporative losses with water supply. To determine net ecosystem exchange, respiratory fluxes, growth and litter fall a simple mass balance carbon allocation-respiration model has been included (Williams et al., 2005; Sus et al., 2010).

Integrating observations and the site-specific model at the ecosystem scale allows the investigation of the relative sensitivity of interacting processes to changes in evaporative demand/temperature and precipitation. Here we applied a novel combination of field experiment, ecosystem observations and the site calibrated soil-plant-atmosphere model. Our objectives were to evaluate the model's ability to capture responses to seasonal drought and reduced soil drought (watering experiment) for a semi-arid regenerating ponderosa pine forest, to determine the sensitivity of carbon and water dynamics to changes in soil and atmospheric drought and to make predictions for scenarios that represent increased drought in the future. Associated with these objectives the following hypotheses were tested: (1) gross primary productivity is more susceptible to changes in atmospheric demand than to changes in summer precipitation, (2) photosynthesis will be more sensitive than heterotrophic respiration to changes in water availability and temperature and (3) increasing summer drought severity will be compensated by lengthening of the growing season.

\section{Methods}

\subsection{Study site}

The study site (US-Me6) is located east of the Cascade mountains in central Oregon ( $977 \mathrm{~m}$ a.s.1., $44^{\circ} 19^{\prime} 25.5^{\prime \prime} \mathrm{N}$, $-121^{\circ} 36^{\prime} 18.4^{\prime \prime} \mathrm{E}$ ) and is part of the Metolius cluster sites within the AmeriFlux network. After a wildfire in 1979 the site was salvage logged, became US Forest Service land and has been re-forested with ponderosa pine trees in 1986 to supplement natural regeneration. Due to poor survival, additional planting was conducted in 1990 . The dominant overstory vegetation is 22 to $26 \mathrm{yr}$ old Pinus ponderosa with an average height of $5.2 \pm 1.1 \mathrm{~m}$ and summer maximum overstory half-sided leaf area index (LAI) of $0.8 \mathrm{~m}^{2} \mathrm{~m}^{-2}$ in 2010. Tree density is low with 162 trees ha ${ }^{-1}$. The understory vegetation is scattered and dominated by antelope bitterbrush (Purshia tridentata (Pursh) D.C.) and grasses (predominantly Bromus tectorum L.), estimated to account for a LAI of $0.1 \mathrm{~m}^{2} \mathrm{~m}^{-2}$. The soil is a freely draining sandy loam ( $82 \%$ sand, $16 \%$ silt, $2 \%$ clay), derived from volcanic 
ash (soil depth $>1.2 \mathrm{~m}$ ). The climate can be characterized as Mediterranean with hot, dry summers and cool, wet springs and winters. The long-term $30 \mathrm{yr}$ (1971-2000) precipitation average for the study site is $460 \mathrm{~mm}$ with large inter-annual variability. Averaged minimum and maximum monthly temperatures range between -5.5 and $10.5^{\circ} \mathrm{C}$ in winter and between 2.5 and $27.8^{\circ} \mathrm{C}$ in summer (PRISM Climate Group, Oregon State University, http://prism.oregonstate.edu, created 31 October 2008).

\subsection{Observational data and experimental setup}

A variety of ecosystem measurements were carried out, including net ecosystem exchange of carbon dioxide $\left(\mathrm{CO}_{2}\right)$ and water $\left(\mathrm{H}_{2} \mathrm{O}\right)$ using the eddy covariance approach, tree transpiration derived from sap flow estimates (heat-dissipation technique), soil and heterotrophic respiration, biomass inventories $(4 \times 17 \mathrm{~m}$ radius plots), leaf area index (in two transects with the LAI-2000, Li-Cor, Lincoln, NB, USA; following Law et al., 2001) and phenological observations in 2010 and 2011. A detailed description of these measurements, data processing and gap-filling of eddy covariance data, as well as partitioning of net ecosystem exchange (NEE) into gross primary productivity (GPP) and ecosystem respiration (Reco) can be found in Ruehr et al. (2012). Because our study focuses on ecosystem $\mathrm{C}$ dynamics, we define net ecosystem productivity as $\mathrm{NEP}=-\mathrm{NEE}$, with positive fluxes meaning $\mathrm{C}$ uptake and negative fluxes $\mathrm{C}$ loss from the ecosystem.

To test the effects of water availability, we conducted a $2 \mathrm{yr}$ watering experiment during the summer drought season (July and August) and compared responses of watered trees and soil to control plots $(n=5$ trees per treatment). In brief, $2 \times 2 \mathrm{~m}$ plots around each tree were irrigated automatically every other night, with 16 pressure-regulated drippers equally distributed every $0.25 \mathrm{~m}^{2}$. The watering was adapted to keep soil moisture near saturation ( $>80 \%$ relative extractable water). In total, $436 \mathrm{~mm}$ of water were applied in 2010 (i.e., $1744 \mathrm{~L}$ per tree) and $582 \mathrm{~mm}$ in 2011 (i.e., $2328 \mathrm{~L}$ per tree). In addition, to account for effects on heterotrophic respiration, we established soil plots in existing gaps within the forest at least $5 \mathrm{~m}$ away from the nearest tree $(0.5 \times 1.5 \mathrm{~m}, n=3$ per treatment $)$. Soil $\mathrm{CO}_{2}$ efflux from these plots reflects mainly heterotrophic respiration (see Ruehr et al., 2012). Soil $\mathrm{CO}_{2}$ efflux was measured half-hourly in automated mode (Li-8100 with Li-8150 multiplexer, Li-Cor, Lincoln, NB, USA) in six plots and every two weeks in manual mode in all plots ( $\mathrm{Li}-6400, \mathrm{Li}-\mathrm{Cor}$, Lincoln, NB, USA). To derive half-hourly heterotrophic respiration $(\mathrm{Rh})$ the rate of automated measured soil $\mathrm{CO}_{2}$ efflux (Rs) was multiplied by the ratio of $\mathrm{Rh} / \mathrm{Rs}$ derived from manual measurements. More details on the irrigation setup and soil $\mathrm{CO}_{2}$ efflux measurements can be found in Ruehr et al. (2012).

Further measurements that have not been reported in Ruehr et al. (2012) are briefly described here. Pre-dawn and midday needle water potentials were measured on 2 south-facing fascicles of 5 trees per treatment on 10 occasions between June and September 2011 using a Scholandertype pressure chamber (PMS, Albany, Oregon). Leaf specific conductance $\left(K_{\text {tree }}\right)$ was calculated from leaf water potential measured at pre-dawn and midday and sap flow measured between 11-13 h (Irvine et al., 2004). Canopy stomatal conductance (Gs) was calculated by a simplified form of the Penman-Monteith equation from sap flow measurements (for details see Ruehr et al., 2012). This approach was suitable because of the well-mixed conditions at our study site.

To estimate the amount of irrigation water taken up by the watered trees we labeled the irrigation water with deuterium. This increased the isotope ratio of $\delta^{2} \mathrm{H}$ in the water from $-98 \%$ o to $+103 \%$ o $\left(\delta^{2} \mathrm{H}\right.$ of water taken up by control trees was $-114 \pm 4 \%$ o). For isotope analysis of tree source water we took branch samples on three occasions during summer 2011, before (17 June) and during the watering treatment (4 August and 22 August) on control and watered trees. Woody branch segments were cut from the trees ( $>15 \mathrm{~cm}$ away from transpiring needles) and immediately transferred to glass vials with Polyseal cone inserts and sealed to prevent evaporation. After cryogenic vacuum distillation, the water extract was analyzed for isotopic composition by isotope spectrometry (DeltaPlus; Finnigan MAT $\mathrm{GmbH}$, Bremen, Germany) interfaced with a temperature conversion/elemental analyzer (TC/EA; Finnigan MAT). The relative amount of tree water that originates from the irrigation was calculated using a simple mixing model: $f 1=$ $\left(\delta\right.$ sample $^{-} \delta$ source $\left._{2}\right) /\left(\delta\right.$ source $_{1}-\delta$ source $\left._{2}\right)$. The $\delta^{2} \mathrm{H}$ values are expressed relative to Vienna Standard Mean Ocean Water.

To derive photosynthetic capacity $\left(V_{\mathrm{cmax}}\right.$ and $J_{\max }$ ) for model parameterization we conducted $\mathrm{A} / \mathrm{Ci}$ curves using a Li-6400 equipped with a Li-6400-02B LED light source (Li-Cor, Lincoln, NB, USA) on south-facing fascicles measured on two occasions once in June and once in July. Leaf temperature was set to $25^{\circ} \mathrm{C}$, photosynthetic radiation to $1600 \mu \mathrm{mol} \mathrm{m}^{-2} \mathrm{~s}^{-1}$ and water vapor concentrations were close to ambient conditions. The $\mathrm{CO}_{2}$ concentrations used to generate the A/Ci curves were 390, 200, 100, 40, $390,500,700,850,1200,1600 \mathrm{ppm}$. A/Ci data was submitted to Leafweb (http://leafweb.ornl.gov/Pages/LeafWeb. aspx) where $V_{\text {cmax }}$ and $J_{\max }$ were calculated by a standardized procedure (Gu et al., 2010).

Measurements of $\mathrm{C}$ stocks for model parameterization are described briefly. Dry weight of root biomass was assessed by sequential coring to $30 \mathrm{~cm}$ soil depth in June, August and September, and visually sorted in fine $(<2 \mathrm{~mm})$ and dead roots (brittle, dark color; see Ruehr and Buchmann, 2010). Maximum rooting depth was estimated at $1.1 \mathrm{~m}$ after excavation of a soil pit, with $80 \%$ of the fine root mass in the $0-60 \mathrm{~cm}$ soil layer. Soil C stock estimates were calculated from measurements of soil $\mathrm{C}$ and bulk density $\left(1.28 \mathrm{~g} \mathrm{~cm}^{-3}\right.$; $0-10 \mathrm{~cm}$ ). We measured $\mathrm{C}$ and $\mathrm{N}$ concentrations of first and second year needles sampled in September 2010 (N content: 
control $1.24 \% \pm 0.04$, watered $1.30 \% \pm 0.03 ; p=0.30$ ). To upscale needle $\mathrm{C}$ and $\mathrm{N}$ to the study site, we multiplied the concentrations with specific leaf area and LAI.

\subsection{The model}

The soil-plant-atmosphere model (SPA), is a process-based model that simulates ecosystem carbon and water balance processes at fine temporal $(30 \mathrm{~min}$ ) and spatial scales (up to 10 canopy and 20 soil layers). The carbon and water cycle in the model is directly coupled with stomatal conductance set to maximize $\mathrm{C}$ gain under limitation of canopy water storage and soil-to-canopy water transport (for details see Williams et al., 2001). To allow for estimates of respiration, $\mathrm{C}$ pool dynamics and total net ecosystem productivity (NEP), the model has been modified with a simple allocation-respiration model (Williams et al., 2005; Sus et al., 2010). The allocation-respiration model (described in detail by Williams et al., 2005) disaggregates GPP into plant respiration and carbon allocation to leaves, fine roots and woody matter assuming fixed allocations. Turnover rates determine the litter fall from leaves and fine roots to the litter pool (fast turnover organic matter) and from woody matter to the soil organic matter pool (SOM; slow turnover). Litter can become part of the SOM pool depending on turnover and mineralization rates. Heterotrophic respiration (Rh) depends on the size of the litter and SOM pools, mineralization rates, temperature and in our modified version, on soil water content (see below). Autotrophic respiration (Ra) depends on the size of the plant respiratory $\mathrm{C}$ pool, the turnover time of this pool and temperature (see below).

In the present study we used SPA v.2.4 (https://www.wiki. ed.ac.uk/display/cesdwiki/SPA) with several adaptations. To improve estimates of soil water potential (SWP), we derived an empirical relationship between soil water content (SWC) and SWP from measurements in 2011 (Supplement Fig. S1), as changes in soil water potentials in the porous soils (e.g., Williams et al., 2001) are only inadequately described by the algorithms normally applied in the model. Our preliminary model testing suggested the ratio of evaporation to ET was too low. Soil evaporation is determined by solving the soilsurface energy balance; evaporation is linked to the thickness of the surface soil crust (i.e. dry soil), which is modeled dynamically. Reducing the roughness layer to $10 \mathrm{~cm}$ in this very open forest stand and by assuming that the soil tortuosity factor of gas diffusion is close to 1 in porous soils (following Moldrup et al., 2001), we were able to increase evaporation estimates by $39 \%$ in 2010 and 2011, improving simulated ET slightly (reduced RMSE by $3 \%$ ). To increase the drought sensitivity in SPA, we added a Weibull function of loss in $K_{\text {tree }}$ to SWP (Supplement Fig. S3), allowing the model to capture the strong drought response of tree transpiration in July and August (see Ruehr et al., 2012).

Concerning the seasonality of carbon fluxes, model testing showed that NEP and GPP were largely overestimated by SPA during winter months and generally had a much reduced seasonality when compared to observations. The reason may be the lack of seasonality of leaf nitrogen and/or photosynthetic capacity in the model. For example, Misson et al. (2006) found that photosynthetic capacity of ponderosa pine shows pronounced seasonality with summer rates of $V_{\mathrm{cmax}}$ and $J_{\max }$ roughly doubling winter rates measured at the same temperature and light conditions. By adding a factor for day-length control (df) to photosynthetic capacity ( $V_{\mathrm{cmax}}$ and $J_{\max }$ with $25^{\circ} \mathrm{C}$ temperature optimum), as found in the CLM4 Community Land Model ( $\mathrm{df}=$ daylength ${ }^{2} /$ max daylength ${ }^{2}$ ), the agreement between simulated and observed daily GPP, Reco and NEP was substantially improved (reduction of RMSE from $0.71-1.06$ to 0.50 $\left.0.73 \mathrm{~g} \mathrm{C} \mathrm{m}^{-2} \mathrm{day}^{-1}\right)$. Further modifications were made to the carbon allocation part of SPA. We included a simple exponential temperature function to turnover of the plant respiratory pool (Ra). For Rh we added a SWC dependency in the form of a sigmoid function to the exponential temperature relationship of mineralization (Supplement Fig. S2).

Because conifer phenology in SPA v.2.4 was practically non-existent (constant $\mathrm{C}$ allocation to growth), yet ponderosa pine shows distinct seasonality of needle growth, we incorporated a relatively simple phenological term derived from 2 years of observations of pine phenology. Roughly, we observed bud break by mid-June with most of leaf elongation in July continuing until the middle/end of August. The peak of needle fall of $4-5 \mathrm{yr}$ old needles occurred by the end of September. The phenology of the deciduous understory shrubs was slightly out of phase. Bud break was up to 1 month earlier and the shrubs were largely without leaves by the end of October. However, for simplification we did not explicitly include the deciduous phenology. To implement the pine phenology in the model, we added a growing degree function starting on 1 February with a $5^{\circ} \mathrm{C}$ threshold (Hannerz, 1999). The growing degree sum was set to 140 after parameterizing to the observed start of bud extension. We used bud extension as the starting point of $\mathrm{C}$ allocation to the needles over bud break (about 10 days later), to represent growth of new plant tissue during bud elongation. After the onset of bud extension (unfolding of buds, but needle tips not green yet), $\mathrm{C}$ allocation to needle growth was activated and ended after 60 days or by 31 August at the latest (we observed that $90 \%$ of needle elongation was completed by mid-August, about 2 months after bud break). In sync with the end of $\mathrm{C}$ allocation to needles, needle turnover (about $6 \%$ needle loss in 30 days) was activated to reduce seasonal needle peak by one-quarter of the initial leaf biomass in spring (i.e., $5 \mathrm{yr}$ old needles). The thereby derived seasonal course of leaf biomass translated into an LAI increase of $0.2 \mathrm{~m}^{2} \mathrm{~m}^{-2}$ during the growing season, with an annual increase in LAI of $0.1 \mathrm{~m}^{2} \mathrm{~m}^{-2}$, which is well within the range of the observed LAI gain of $0.08 \mathrm{~m}^{2} \mathrm{~m}^{-2}$ between 2010 and 2011 . 


\subsubsection{Simulation and parameterization}

The model was run using half-hourly meteorological data (including temperature, $\left[\mathrm{CO}_{2}\right]$, wind speed, shortwave radiation, vapor pressure deficit, photosynthetic active radiation and precipitation) for $3 \mathrm{yr}$ (2009-2011), where 2009 was used as a spin-up run for soil water content and soil temperature. We divided the canopy in five layers of equal height with varying leaf biomass. For simplification all layers including the understory were treated as ponderosa pine. Leaf nitrogen content was split equally among the layers, as we did not assume nitrogen to vary substantially with height in the open canopy. For the soil, we assigned 20 soil layers up to $2 \mathrm{~m}$ depth, each layer $10 \mathrm{~cm}$ thick with constant soil texture.

Most of the data needed for model parameterization were available from measurements (see Tables 1 and 2). Some parameter estimates were derived from Williams et al. (2005) who used data assimilation to parameterize carbon allocation in SPA. These parameters were adjusted with an iterative technique to produce the best agreement with observations (defined by minimum RMSE and highest $R^{2}$ between simulated and measured values). First, parameters of the SPA core model were calibrated. Estimates of stem conductivity and root resistivity were derived from leaf-specific hydraulic conductance ( $K_{\text {tree }}$, see above). We used these data as the starting point to calibrate simulations with measured daily SWC and tree transpiration. We calibrated the model to follow the dynamics in observed transpiration, but allowed the model to overestimate tree transpiration to account for the transpiration of understory herbs and shrubs (LAI of about $0.1 \mathrm{~m}^{2} \mathrm{~m}^{-2}$ ) and to match ET observations. Allocation of $\mathrm{C}$ to leaf growth was the next parameter adjusted to produce leaf biomass close to measured LAI by the end of summer. The allocation to fine root growth was calibrated in two ways, by checking the drought sensitivity of simulated transpiration, and by ensuring that wood growth over the 2 years equaled stem area increment estimates from dendrometer bands (11\% observed vs. $12 \%$ modeled wood increment in 2011), resulting in an average annual increase in fine root biomass of $10 \%$. Next, the mineralization rate of SOM and the turnover rate of litter to SOM was tuned to improve estimates of Rh during the two growing seasons. Then we calibrated the parameters that determine the fraction of GPP respired and the turnover rate of the Ra pool to improve the match of simulated and observed NEP and Reco. Finally, we re-checked the fit of the simulations with the observations and if necessary repeated the calibration steps once more. Data processing and statistical analyses were performed using R 2.11.1 (R Development Core Team, 2010).

\subsubsection{Climate scenarios}

The future climate for the Pacific Northwest was implemented from the A1B greenhouse gas emission scenario, derived from a suite of models by reliability ensemble av- eraging (Center for Science in the Earth System, University of Washington; 2008 scenarios: http://cses.washington. $\mathrm{edu} / \mathrm{cig} / \mathrm{fpt} / \mathrm{ccscenarios}$.shtml). In general, all seasons are expected to be warmer with the largest temperature increase predicted during summer. Modest changes in precipitation are expected, although changes in precipitation are less certain than changes in temperature. Small increases in precipitation are likely to occur during winter (approx. +4 \% in 2040 and $+8 \%$ in 2080), while slight precipitation decreases are expected during summer (approx. $-12 \%$ in 2040 and $-16 \%$ in 2080).

To test the sensitivity of the young pine stand to changes in forcing, simulations were run over $10 \mathrm{yr}$ starting from the same initial conditions with different climate imposed. The $10 \mathrm{yr}$ long data series of future temperature, vapor pressure deficit (VPD) and precipitation were created by iterating the years 2010 and 2011 and adding the expected temperature increase and $-10 \%$ and $-20 \%$ percent changes in summer precipitation (2010 and 2011 were relatively average years and well within the 1971-2000 temperature and precipitation range derived from PRISM Climate Group, http: $/ /$ prism.oregonstate.edu). Meteorological data from 2009 was changed accordingly and used in the spin-up run. Because extreme events are likely to increase, rain amounts were experimentally reduced by $50 \%$ and $100 \%$ between June and August and simulations run accordingly. We tested the sensitivity to the following scenarios: (a) reduced summer precipitation, (b and c) increased summer temperatures (2040 and 2080) in combination with reductions in summer precipitation and (d and e) warming across all seasons (2040 and 2080) in combination with reductions in summer precipitation. Because long-term stimulating effects of $\mathrm{CO}_{2}$ on productivity are highly uncertain, especially under changing water availability (see Nowak et al., 2004), and in addition are limited by nitrogen availability for which SPA does not account for in its current form, all future climate scenarios were implemented under current atmospheric $\mathrm{CO}_{2}$ concentrations of $390 \mathrm{ppm}$.

\subsection{Error estimates}

We derived observational errors from standard deviations between plots and measurement campaigns if suitable (see Tables 1 and 2). The error of annual net ecosystem exchange sums from eddy covariance was estimated at $\pm 16 \%$ at a young pine site close by (Vickers et al., 2012). Since NEP fluxes can be positive or negative, defining errors by a coefficient of variation is unsuitable, so instead the error of daily NEP was set at $\pm 0.5 \mathrm{~g} \mathrm{C} \mathrm{m}^{-2} \mathrm{~d}^{-1}$ (see Williams et al., 2005). Error estimates for daily evapotranspiration $\left(\mathrm{ET}_{\mathrm{obs}}\right)$, gross primary productivity $\left(\mathrm{GPP}_{\mathrm{obs}}\right)$, ecosystem respiration $\left(\right.$ Reco $\left.{ }_{\text {obs }}\right)$ and heterotrophic respiration fluxes $\left(\mathrm{Rh}_{\mathrm{obs}}\right)$ were set at $\pm 20 \%$, similar to the error of annual net ecosystem exchange sums. The error estimate for absolute stand-scaled tree transpiration $\left(\mathrm{T}_{\mathrm{obs}}\right)$ was set at $\pm 40 \%$, calculated from 
Table 1. Key parameter values for the soil-plant-atmosphere model.

\begin{tabular}{|c|c|c|c|c|}
\hline Parameter & Unit & Model value & SD & Derived \\
\hline Foliar N & $\mathrm{g} \mathrm{N} \mathrm{m}^{-2}$ leaf area & 3.11 & \pm 0.22 & measured \\
\hline Stem conductivity & $\mathrm{mmol} \mathrm{m}^{-1} \mathrm{~s}^{-1} \mathrm{MPa}^{-1}$ & 10 & \pm 2 & estimated from $K_{\text {leaf }} *$ \\
\hline Minimum leaf water potential & $\mathrm{MPa}$ & -1.8 & \pm 0.1 & measured \\
\hline Leaf capacitance & $\mathrm{mmol} \mathrm{m}^{-2} \mathrm{MPa}^{-1}$ & 3000 & - & estimated* \\
\hline Root resistivity & MPa s g mmol-1 & 20 & \pm 10 & estimated from $K_{\text {leaf }} *$ \\
\hline Rate constant for $V_{\text {cmax }}$ & $\mu \mathrm{molg} \mathrm{N^{-1 }} \mathrm{s}^{-1}$ & 31.4 & \pm 3 & measured (A/Ci curves) \\
\hline Rate constant for $J_{\max }$ & $\mu \mathrm{molg} \mathrm{N^{-1 }} \mathrm{s}^{-1}$ & 60.6 & \pm 5 & measured (A/Ci curves) \\
\hline Leaf $\mathrm{C}$ & $\mathrm{gC} \mathrm{m}^{-2}$ & 122.4 & \pm 3.6 & measured \\
\hline Maximum root depth & $\mathrm{m}$ & 1.1 & \pm 0.1 & measured \\
\hline Root biomass ${ }^{\mathrm{a}}$ & $\mathrm{gC} \mathrm{m}^{-2}$ & 70 & \pm 20 & measured* \\
\hline Sand & $\%$ & $82 \%$ & - & measured* \\
\hline Clay $b$ & $\%$ & $2 \%$ & - & measured* \\
\hline
\end{tabular}

a Root biomass to $50 \%$ rooting depth.

* Adjusted during model parameterization; see Methods for details.

Table 2. Key parameter values for the carbon allocation-respiration part of the soil-plant-atmosphere model. Biomass $\mathrm{C}$ is given in $\mathrm{g} \mathrm{m}^{-2}$.

\begin{tabular}{|c|c|c|c|c|}
\hline Parameter & Description & Model value & Error & Derived \\
\hline $\mathrm{Cf}$ & Foliar $\mathrm{C}$ initial & 72 & \pm 7.2 & measured (interpolated) \\
\hline $\mathrm{Cw}$ & Wood $\mathrm{C}$ initial & 400 & \pm 80 & measured (allometrics) \\
\hline $\mathrm{Cr}$ & Fine $\operatorname{root} \mathrm{C}$ initial & 80 & \pm 20 & measured (interpolated) \\
\hline Clit & Fresh fine litter $\mathrm{C}$ initial & 20 & \pm 10 & Williams et al. $(2005)^{*}$ \\
\hline Csom & SOM C initial & 5000 & \pm 500 & measured (interpolated) \\
\hline fa & Fraction of GPP respired $^{\mathrm{a}}$ & 0.49 & - & Williams et al. (2005)* \\
\hline $\mathrm{nf}$ & NPP allocated to foliage & 0.2 & - & Williams et al. $(2005)^{*}$ \\
\hline nrr & NPP allocated to fine roots & 0.6 & - & Williams et al. $(2005)^{*}$ \\
\hline $\mathrm{dc}$ & Turnover of litter to SOM & $4.63 \times 10^{-4}(90 \mathrm{~d})$ & - & Williams et al. $(2005)^{*}$ \\
\hline $\mathrm{tf}$ & Turnover rate of foliage ${ }^{b}$ & $8.00 \times 10^{-5}(1.4 \mathrm{yr})$ & - & measured* \\
\hline tw & Turnover rate of wood ${ }^{\mathrm{c}}$ & $2.28 \times 10^{-5}(5 \mathrm{yr})$ & - & Williams et al. $(2005)^{*}$ \\
\hline $\operatorname{tr}$ & Turnover rate of fine roots & $1.67 \times 10^{-4}(0.68 \mathrm{yr})$ & - & Andersen et al. (2008) \\
\hline $\mathrm{ml}$ & Mineralization rate of litter & $1.16 \times 10^{-4}(1 \mathrm{yr})$ & - & Kelliher et al. (2004) \\
\hline $\mathrm{ms}$ & Mineralization rate of SOM / CWD ${ }^{\mathrm{d}}$ & $3.81 \times 10^{-6}(30 \mathrm{yr})$ & - & Williams et al. $(2005)^{*}$ \\
\hline $\operatorname{tar}$ & Turnover rate of Ra pool & $1.39 \times 10^{-3}(30 \mathrm{~d})$ & - & estimated * \\
\hline resprate & $\mathrm{Rh}$ temperature response & 0.044 & - & measured* \\
\hline aresprate & Ra temp response & 0.025 & - & measured* (leaf respiration) \\
\hline gdtsum & Bud expansion: GDS ${ }^{\mathrm{e}}$ & 140 & - & measured* \\
\hline
\end{tabular}

${ }^{a}$ Increased by 0.05 during winter (November-March).

b Turnover of $12 \%$ needles in $60 \mathrm{~d}$ (September-October).

c Turnover of $20 \%$ wood $\mathrm{yr}^{-1}$.

d CWD (coarse woody debris).

${ }^{\mathrm{e}}$ GDS (growing degree sum) $=($ gdd + avtemp -5$)$; starting 1 February $($ Hannerz, 1999)

* Adjusted during model parameterization; see Methods for details.

NPP (net primary productivity).

standard error of sap flux between trees, the error of standscaled sapwood calculation and estimates of decreasing sap flux density with sapwood depth (Irvine et al., 2004). The error for SWC was set at $\pm 0.2 \mathrm{~m}^{3} \mathrm{~m}^{-3}$ as given by the manufacturer (10HS, Decagon Devices, Inc., WA, USA).
The error of simulated daily GPP due to parameter uncertainties estimated to range between $\pm 10 \%$ and $\pm 20 \%$ derived from sensitivity analysis of SPA. (for more details see Williams et al., 2001, 2005). 


\section{Results}

\subsection{Seasonality and drought response}

The seasonality of the 2 study years was pronounced, with coldest temperatures during winter dropping as low as $-25^{\circ} \mathrm{C}$, and maximum temperatures up to $34^{\circ} \mathrm{C}$ during the mainly dry summer months of July and August. Similarly, observed ecosystem water and $\mathrm{CO}_{2}$ exchange was lowest during winter and peaked before or at the beginning of the dry season (Figs. 1 and 2) that extended from mid-June to September in both study years. Despite different patterns in precipitation variability during the two summer seasons, the amount of rain from June to August was similar with $52 \mathrm{~mm}$ and $53 \mathrm{~mm}$ (about $12 \%$ of annual precipitation), and SWC $(0-40 \mathrm{~cm})$ was as low as $0.05 \mathrm{~m}^{3} \mathrm{~m}^{-3}$ by September during both years (Fig. 1c and d). Ecosystem fluxes declined strongly after the last summer rain event along with increasing soil and atmospheric drought (Figs. 1 and 2). The tight water-limitation of ecosystem processes was also reflected by the ratio of annual precipitation to ET being closely balanced. Nevertheless, the ecosystem was a significant $\mathrm{C}$ sink, with $241 \mathrm{~g} \mathrm{C} \mathrm{m}^{-2} \mathrm{yr}^{-1}$ in 2011 (Table 3) with about $50 \%$ of annual NEP occurring during the often cool, but relatively wet months of May and June, and only $20 \%$ during the dry months of July and August.

Seasonality and drought responses of ecosystem fluxes were well captured by the SPA model. The performance of the model to estimate flux dynamics has been confirmed by linear regressions between simulated and observed daily fluxes $\left(R^{2}=0.63-0.87\right.$; Fig S3). Generally, simulated C fluxes matched the observations very well and the percent mean bias ranged from 3-17\%. Annual GPP sim $_{\text {and }}$ Recosim were larger compared to the observations caused by higher fluxes during early spring in both years. These overestimations were outbalanced and the resulting $\mathrm{NEP}_{\text {sim }}$ agreed very well with only $14 \mathrm{~g} \mathrm{C} \mathrm{m}^{-2} \mathrm{yr}^{-1}$ or less than $10 \%$ difference between simulated and observed values in 2011 (Table 3).

We found larger divergences between simulated and observed water fluxes, especially during the summer season. $\mathrm{ET}_{\text {sim }}$ was smaller than $\mathrm{ET}_{\mathrm{obs}}$ by an average of $41 \%(76 \mathrm{~mm})$ during summer 2010 and $29 \%$ (58 mm) during summer 2011 (Supplement Fig. S3c). The large differences in ET during summer 2010 coincided with low average contributions of soil evaporation to ET in the model (15\% on average), zero on most days between mid-July and August. However, the imbalance in modeled and observed annual ET $(-67 \mathrm{~mm})$ was largely outbalanced by $58 \mathrm{~mm}$ of water lost via drainage from the model's $2 \mathrm{~m}$ soil column. Moreover, the good agreement between modeled and observed SWC $(0-40 \mathrm{~cm})$ indicates that the amount of water available for plants should have been similar between model and observation. This is also indicated by the dynamics of observed and modeled $\mathrm{T}$ agreeing well, but absolute flux rates were overestimated by the model (Figs. 1g-h). This overestimation was intentional
Table 3. Annual sums of net ecosystem productivity (NEP), gross primary productivity (GPP) and ecosystem respiration (Reco) derived from simulations with the SPA model (sim) and observations (obs) that were partitioned and gap-filled from measurements of net ecosystem exchange (available from March 2010).

\begin{tabular}{lcccccc}
\hline & Year & $\begin{array}{c}\text { NEP } \\
\left(\mathrm{g} \mathrm{C} \mathrm{m}^{-2} \mathrm{yr}^{-1}\right)\end{array}$ & $\begin{array}{c}\text { GPP } \\
\left(\mathrm{mm} \mathrm{yr}^{-1}\right)\end{array}$ \\
\hline sim & 2010 & 175 & 895 & 720 & 316 & 455 \\
sim & 2011 & 228 & 968 & 740 & 358 & 430 \\
obs & 2011 & 242 & 850 & 608 & 425 & 430 \\
\hline
\end{tabular}

to allow for understory transpiration (about $15 \%$ of LAI), and to improve the fit with the whole ecosystem ET and GPP observations. Upscaling sap flow measurements from single trees to estimate study site transpiration is generally prone to larger errors. Here, we estimated the error of site-level $\mathrm{T}_{\text {tree-obs }}$ to be $\pm 40 \%$. In this context, and not having understory $\mathrm{T}$ measurements, a $60 \%$ bias between $\mathrm{T}_{\text {tree-obs }}$ and $\mathrm{T}_{\text {sim }}$ (Supplement Fig. S3d) seems reasonable.

Summarizing, despite some discrepancies between simulated and observed ET during summer, we can highlight that the modified SPA model performed generally well in capturing the seasonality as well as drought response of water and carbon fluxes in the regenerating semi-arid pine forest.

\subsection{Effects of decreased soil and atmospheric drought}

To quantify the effects of soil water limitation on the pines' physiology, we conducted a summer irrigation experiment with soil water content close to field capacity $\left(0.23 \mathrm{~m}^{3} \mathrm{~m}^{-3}\right)$. Nevertheless, pre-dawn leaf water potentials (i.e., soil water potential) of watered trees declined from a pre-drought maximum of $-0.4 \mathrm{MPa}$ to $-0.7 \mathrm{MPa}$ counterintuitive given the large soil water content (see Supplement Fig. S1). Along with the decline in SWP, tree transpiration decreased by $20 \%$ and tree conductivity by $40 \%$ (Fig. 3). This indicates that watered trees experienced a mild water limitation, despite the large amount of water added. Thus, water available to the trees must have been less than indicated by SWC measurements. A likely explanation is that the area watered $\left(4 \mathrm{~m}^{2}\right.$ around each tree) was too small to cover the horizontal root distribution of the trees. Nevertheless, the watering clearly affected the trees' hydraulics and resulted in T being larger by $15 \%$ in watered compared to control trees. Isotope analysis of $\delta \mathrm{H}^{2}$ in tree source water confirms that the additional water available for transpiration was from the irrigation $(21 \pm 7 \%$ on 4 August and $20 \pm 3 \%$ on 22 August 2011). In addition, our observations showed that changes in stomatal conductance (Gs) depend on available water, but with variations of VPD superimposed, for example Gs increased by $100-400 \%$ under low compared to high VPD conditions (Fig. 3b).

To further study the effects of reduced drought on ecosystem fluxes, and because our field experiment only partially 


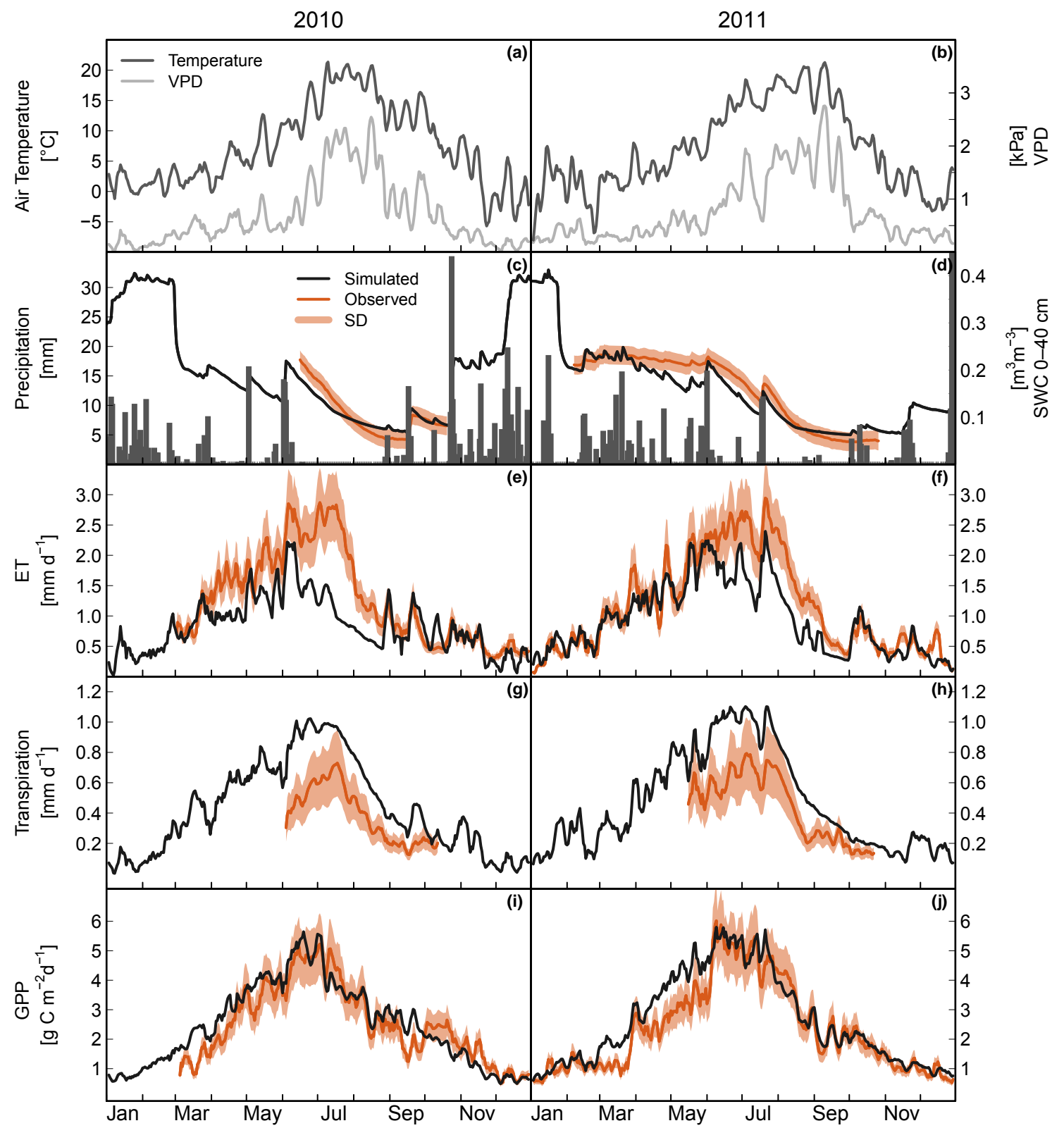

Figure 1. Seasonality of daily meteorological conditions (a-d) and observed and simulated evapotranspiration (ET, e and f), transpiration (g and $\mathbf{h}$ ) and gross primary productivity (GPP, i and j) during 2010 and 2011. Bars are sums of daily precipitation, and observed and simulated soil water content (SWC) are daily averages. Simulated wintertime SWC above field capacity $\left(>0.23 \mathrm{~m}^{3} \mathrm{~m}^{-3}\right)$ results from surface layer freezing. Air temperature, daytime vapor pressure deficit (VPD) and flux data are 5 day moving averages. Error estimates (SD) for observational data are given by the lighter colored areas around the mean. Note that observed transpiration fluxes do not include understory transpiration.

removed water limitation, we simulated the irrigation treatment using the SPA model ( $\left(100_{\text {sim }}\right)$. Additionally, to quantify the effects of atmospheric drought on GPP, we run the simulations under low VPD conditions. To test if the observations from the field experiment could be reproduced by the model, the amount of water added was reduced stepwise in the simulations (e.g., w 40 sim corresponds to $40 \%$ of water added).
Soil drought in the simulation (w100 sim) was eliminated when applying the same amount of water as in the field experiment (Fig. 4). $\mathrm{SWP}_{\text {sim }}$ remained at $-0.4 \mathrm{MPa}$ (Supplement Fig. S4), resulting in larger $\mathrm{T}_{\text {sim }}$ and $\mathrm{GPP}_{\text {sim }}$ fluxes compared to the summer baseline conditions (JuneSeptember, Table 4). Nevertheless, GPP ${ }_{\text {sim }}$ continued to decrease during the summer season, while $\mathrm{T}_{\text {sim }}$ remained relatively constant (Fig. 4c-f). The increase in VPD during 


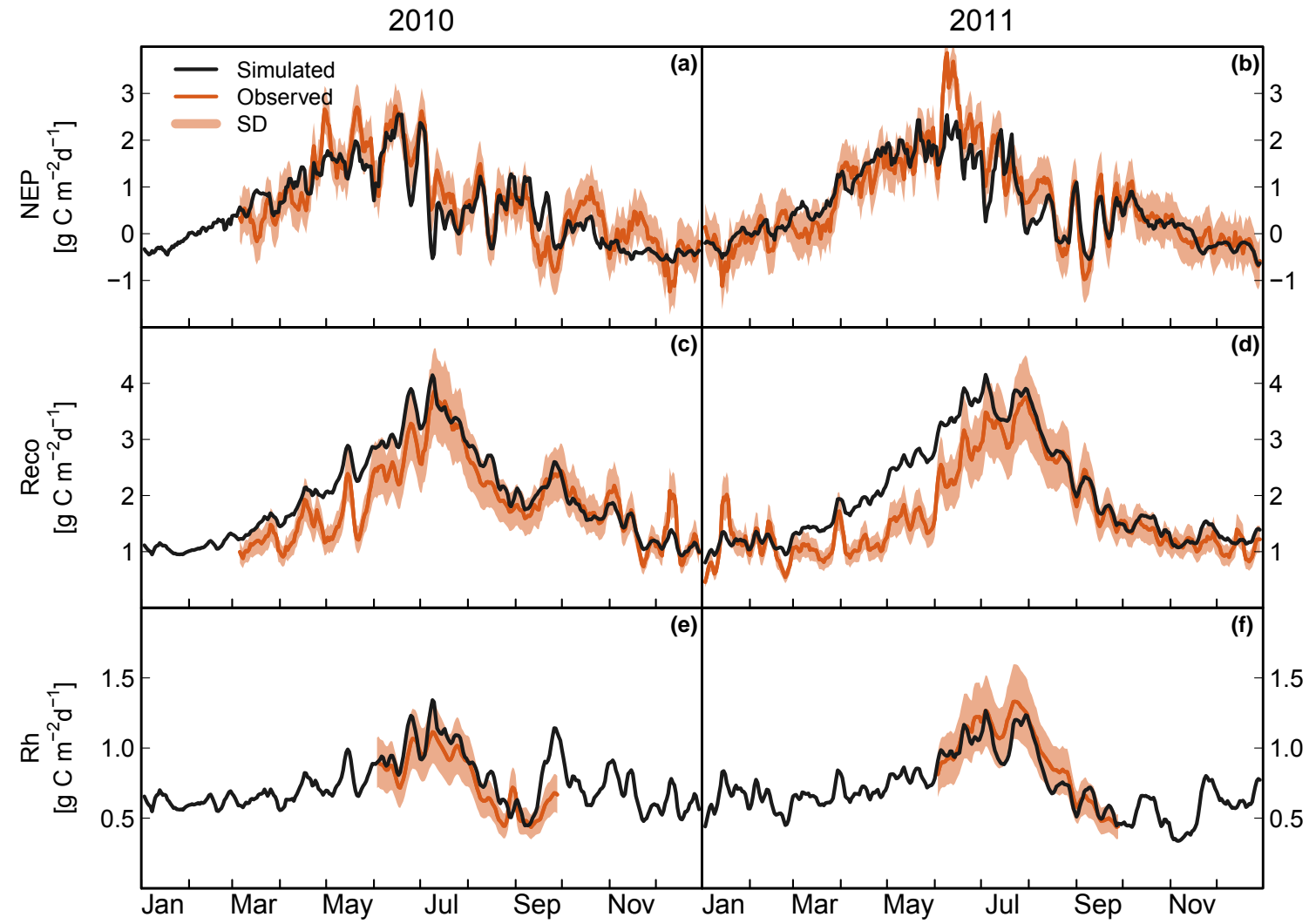

Figure 2. Seasonality of observed and simulated daily net ecosystem productivity (NEP, a and b), ecosystem respiration (Reco, $\mathbf{c}$ and $\mathbf{d}$ ) and heterotrophic respiration (Rh, e and f) in 2010 and 2011. Data are 5 day moving averages. Error estimates (SD) for observational data are given by the lighter colored areas around the mean.

the summer season at relative constant $\mathrm{T}$ reduces Gs which causes GPP to decline. The dominant effect of VPD was confirmed by the low VPD scenario (w100_vpd1 $1_{\text {sim }}$ ), with $\mathrm{GPP}_{\text {sim }}$ rates maintaining at early summer conditions (Fig. 4e and f).

Comparing observations with the w $100_{\text {sim }}$ showed that heterotrophic respiration agreed well (not affected by small plot size), while the effects on tree hydraulics were, as expected, larger under simulated than field conditions. The best agreement between observed and simulated SWP was found for the $30 \%$ irrigation scenario (w30 $0_{\text {sim }}+174 \mathrm{~mm}$, see Supplement Fig. S4) in 2011. This was suggested by the percentage of irrigation water taken up (20\% under field conditions derived from isotope labeling, and $22 \%$ in the $\mathrm{w} 30_{\text {sim }}$ scenario) and further confirmed by the relative increase in $\mathrm{T}_{\mathrm{obs}}$ $(+23 \%)$ and $\mathrm{T}_{\text {sim }}(+28 \%)$ during July and August compared to the "normal" summer drought conditions.

\subsection{Climate scenarios}

To evaluate the effects of intensifying droughts and warmer temperatures on the carbon and water balance of the young pine plantation, we ran SPA over a $10 \mathrm{yr}$ period starting from the same initial conditions but with different climate sce- narios imposed $\left(\mathrm{CO}_{2}\right.$ concentrations remained at 2010/2011 conditions). Percent responses were calculated from averaged annual changes relative to the $2010 / 11$ control conditions.

Summer rain (June-August) was reduced without changing its variability, stepwise by $10,20,50$ and $100 \%$ (i.e., $100 \%$ reduction is about $-52 \mathrm{~mm}$ or $-12 \%$ annually; resulting in summer SWC reduction of $20 \%$ ). These reductions in summer rain are similar to the dry years in the early 2000 s with precipitation anomalies of $-31 \%$ to $-85 \%$ during summer (compared to the average summer precipitation of $43 \mathrm{~mm}$ between 1971 and 2010; PRISM Climate Group). As expected, no rain caused the strongest decline in all fluxes with $8 \%$ to $12 \%$, but the decrease with declining summer precipitation was not linear (Fig. 5a). The decline in NEP to $50 \%$ summer rain reduction $(-7 \%)$ was nearly as large as under $100 \%$ rain reduction $(-8 \%)$. The response of $\mathrm{Rh}$ and GPP followed similar patterns, but the relative decrease in Rh was slightly less than that of GPP.

Increased summer heat of up to $38.5^{\circ} \mathrm{C}$ had a pronounced negative effect on simulated annual fluxes (Fig. $5 \mathrm{~b}$ and c), biomass and soil organic matter (Fig. 6b and c). This was contrasted by Rh being relatively unaffected, causing NEP to decline sharply. An increase in summer temperatures of 


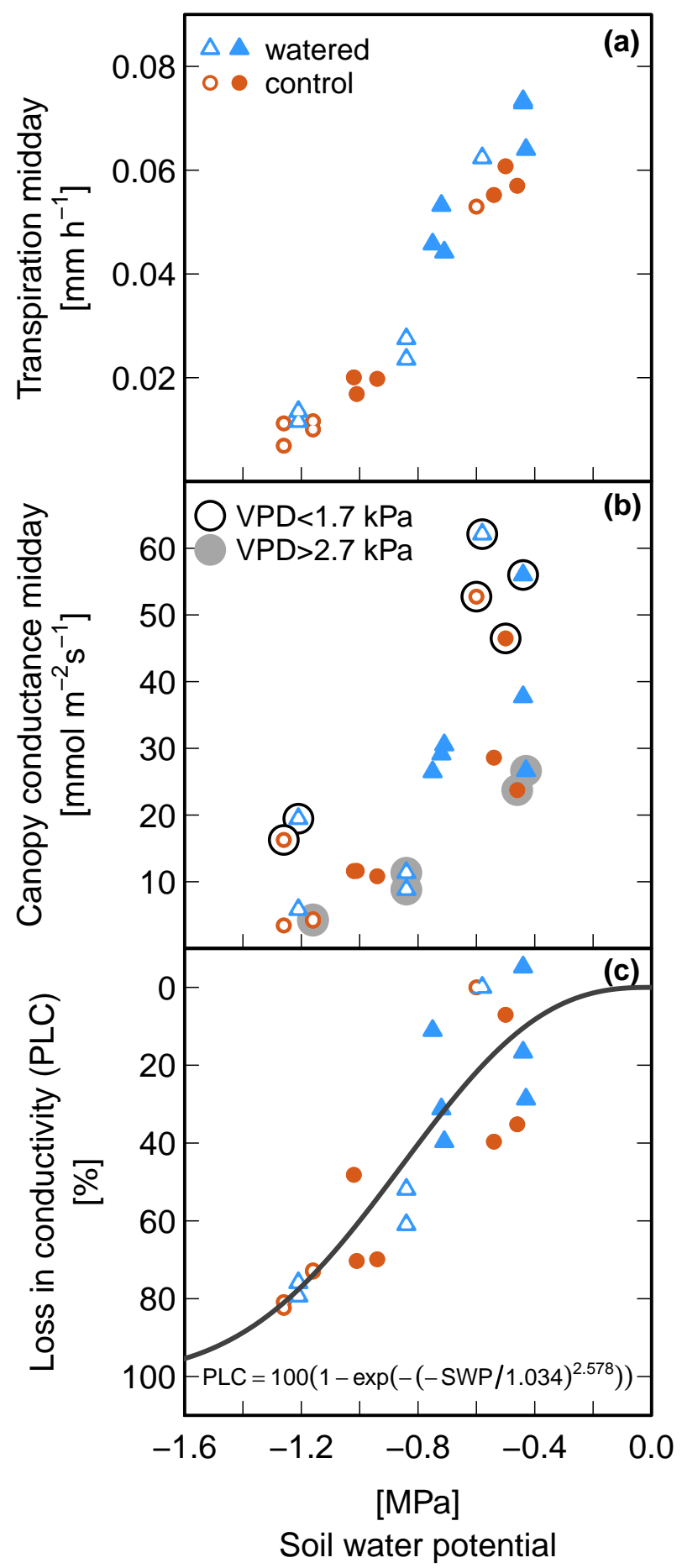

Figure 3. Changes in tree-water relations with declining soil water potential (SWP; i.e., pre-dawn leaf water potential) for control and watered trees during summer 2011. Shown are changes in (a) midday tree transpiration, (b) midday canopy conductance affected by changes in VPD and (c) percent loss in tree conductivity (PLC). Open symbols indicate measurements taken outside the irrigation period in June and September. The relationship of PLC with SWP is represented by a Weibull function that has been integrated in the modified SPA model.
$+3{ }^{\circ} \mathrm{C}$ and $+4.5^{\circ} \mathrm{C}$, along with a $30 \%$ and $40 \%$ increase in VPD, led to a $-24 \%$ and $-38 \%$ reduction in net ecosystem carbon uptake (Fig. $5 \mathrm{~b}$ and c). SPA did not predict pronounced interactive heat and drought effects. For example, in response to 2080 summer temperatures and $100 \%$ rain reduction, the simulated $49 \%$ decline in NEP was almost additive $\left(+4.5{ }^{\circ} \mathrm{C}:-38 \%\right.$ and $-100 \%$ rain: $\left.-8 \%\right)$. Increasing the length of the model runs (i.e., from 2010-2080), would probably allow for further acclimation and feedback of the responses.

Ecosystem fluxes were stimulated by the warmer winter/spring conditions under the full 2040 and 2080 temperature scenarios at current $\left[\mathrm{CO}_{2}\right]$, offsetting some of the negative effects of hotter summers (Fig. 5d and e). Nevertheless, soil organic matter declined (2040: $-1.7 \%$ and 2080: $-2.1 \%$; Fig. 6d and e), because Rh increased more in response to the warming (2040: $+5 \%$ and $2080+8 \%$ ) than GPP (Fig. 5d and e). Taking a closer look on the seasonal course of differences in averaged cumulative fluxes reveals interesting patterns (Fig. 7). Cumulative GPP and NEP were much larger during the first half of the year under the 2040 and 2080 scenarios compared to the 2010/11 baseline (Fig. 7a and b, solid lines). The warmer winter/spring temperatures improved the conditions for photosynthesis and also caused bud elongation to occur earlier (5 May in 2080 vs. 6 June in 2010/11). Accordingly, the model predicted cumulative GPP to be $100 \mathrm{~g} \mathrm{C} \mathrm{m}^{-2}$ and NEP to be about $40 \mathrm{~g} \mathrm{C} \mathrm{m}^{-2}$ larger on average by June in 2080 compared to the 2010/11 reference. This difference in cumulative fluxes decreased sharply at the onset of the summer dry season (Fig. 7a and b). Interestingly, net ecosystem $\mathrm{C}$ uptake under the 2080 scenario remained below the 2010/11 reference despite an increase in needle biomass (Fig. 6d and e). Larger needle biomass was accompanied by a small decrease in root and woody biomass, which caused the needle to root ratio to increase (Fig. 6d and e). An imbalance in the abovegroundto-belowground biomass ratio could lead to an increase in drought stress over the long term, with a possible threshold at which ponderosa pine may not survive.

\section{Discussion}

\subsection{Model evaluation}

Our modified and calibrated version of the SPA model did successfully simulate the observed seasonality and drought response of a semi-arid ponderosa pine forest. Simulated net ecosystem $\mathrm{C}$ uptake was within the uncertainty estimates of the observation in 2011. Simulated annual ET estimates were underestimated but still within the observational error. The net effect on the water balance was likely small, as soil drainage in the model closely balanced the underestimation of ET and soil water content between model and observations agreed well. 


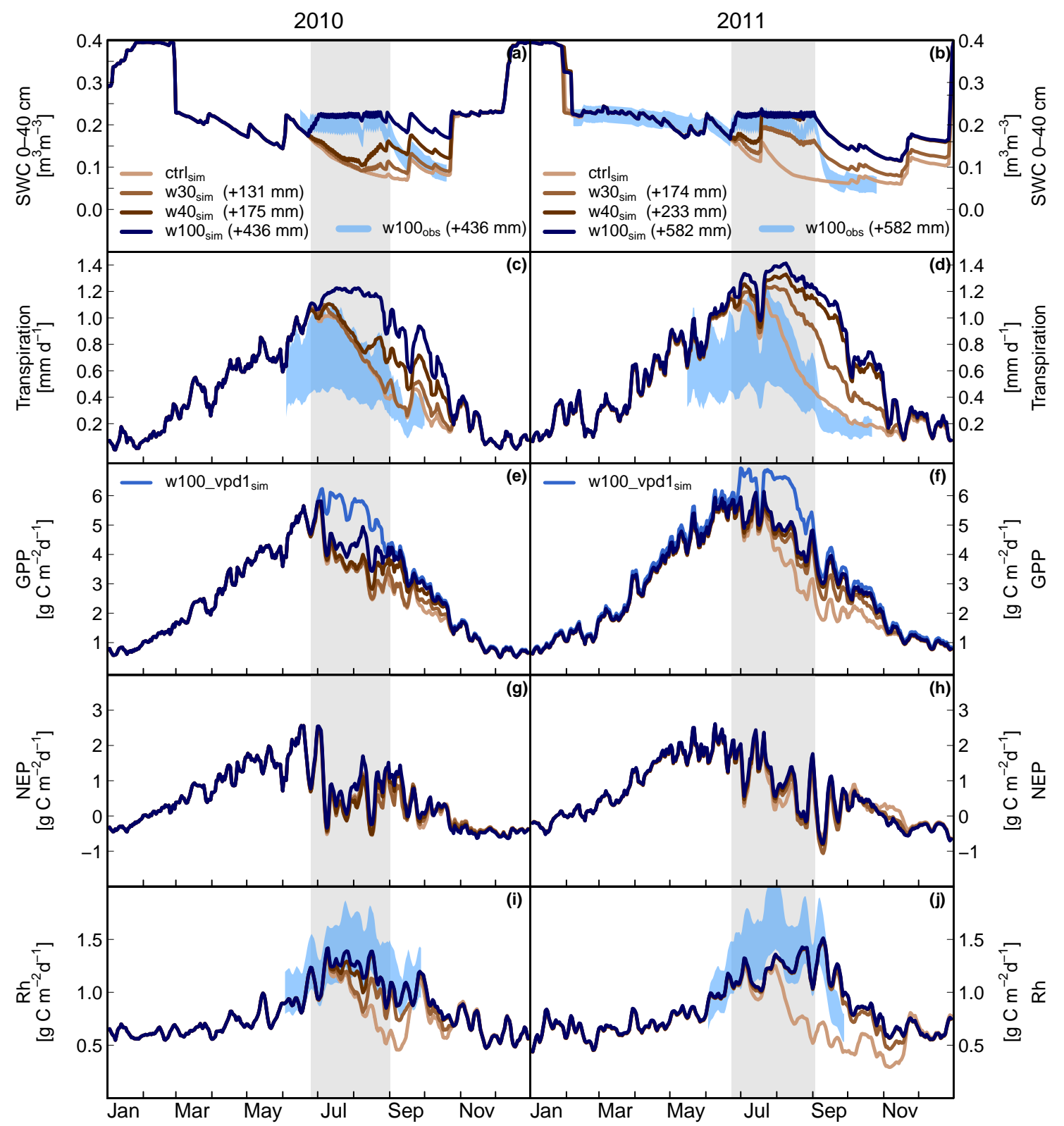

Figure 4. Effects of experimentally decreased summer drought on soil water content (SWC; $\mathbf{a}$ and $\mathbf{b})$, transpiration (T; $\mathbf{c}$ and $\mathbf{d}$ ) and carbon

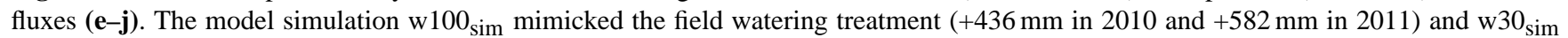
and $\mathrm{w}_{40} \mathrm{sim}_{\text {im }}$ are 30 and $40 \%$ of irrigation water added; the $\mathrm{ctrl}_{\text {sim }}$ is the "normal" summer drought. The limiting effect of VPD on GPP is indicated by running the $\mathrm{w} 100_{\text {sim }}$ scenario at low VPD conditions of $1 \mathrm{kPa}$ (e) and (f). Note that simulated wintertime SWC above field capacity $\left(>0.23 \mathrm{~m}^{3} \mathrm{~m}^{-3}\right)$ results from surface layer freezing. Observations of SWC, T and heterotrophic respiration (Rh) in the watered treatment ( $\left(100_{\mathrm{obs}}\right)$ are depicted by the light colored area (mean \pm error estimate). The duration of the water additions is highlighted in gray.

Larger differences between simulated and measured ET during summer have been found in other pine forests using SPA (Schwarz et al., 2004). A likely explanation for the differences in ET between observations and the model might be the hydraulic lift of water via roots from moist to drier soil layers, which occurs in many ecosystems. In a study on loblolly pine, hydraulic lift was found to account for 15$25 \%$ of the ecosystem's water loss during the dry summer months (Domec et al., 2010). However, the good agreement of the ratio of tree $\mathrm{T}$ to ET in our study $(27 \pm 10 \%)$ with a young forest of pines close by (Irvine et al., 2004) and the much larger simulated stand transpiration (T /ET ratio of 70$90 \%$, including over- and understory) does not indicate that water loss via transpiration was missed by the model. It is more likely that soil evaporation was underestimated by SPA. A possible explanation could be an overestimation of shallow 


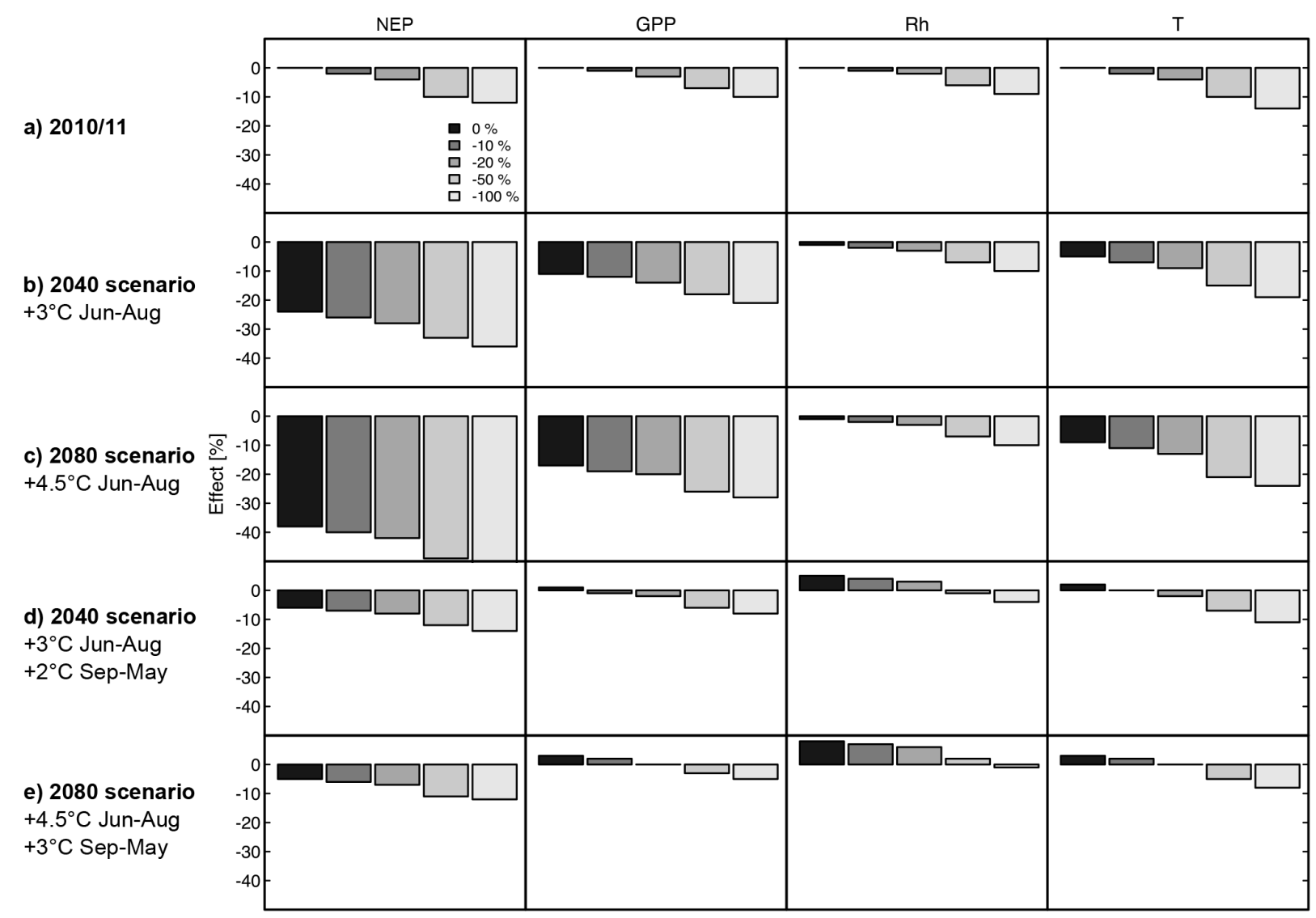

Figure 5. Effects of reduced precipitation and increased temperatures on simulated ecosystem fluxes. Percent mean annual changes of the $10 \mathrm{yr}$ model runs relative to the $2010 / 11$ control conditions ( $0 \%$ rain reduction) are given. Precipitation from June to August was decreased by $0,10,20,50$ and $100 \%$ (10 and $20 \%$ reductions are in accordance with the climate scenarios for 2040 and 2080). 2010/11 control temperature (a), only summer temperature increased (b) and (c), all-seasons temperature increased (d) and (e). Note that $\mathrm{CO}_{2}$ concentrations were $390 \mathrm{ppm}$ for all scenarios.

root density that decreases water partitioning towards evaporation; also, large spatial variability in root distribution may play a significant role. Moreover, in very open forest stands, like our study site (162 tree ha ${ }^{-1}$ with about $25 \%$ canopy cover and LAI varying from 0 to $2 \mathrm{~m}^{2} \mathrm{~m}^{-2}$ ), net radiation transmitted to the forest floor can be larger than a multilayer canopy model with equal leaf distribution implies, resulting in an underestimation of soil evaporation (Law et al., 2001). Indeed, a study in a semi-arid pine forest in Israel shows that soil evaporation can vary substantially between sun-exposed and shaded areas, and indicates that at a canopy cover of about $25 \%$, half of the annual precipitation evaporates from the soil (Raz-Yaseef et al., 2010). Applying this ratio to annual precipitation measured at our study site suggests that soil evaporation estimates from SPA might be 30 $40 \%$ too low. Thus, including the heterogeneous nature of open forest stands in canopy cover and root distribution may improve evaporation predictions especially in Mediterranean and semi-arid regions.
Considering drought effects, we found SPA to perform well in predicting the decline of measured component fluxes. The earlier and stronger reduction in GPP than Reco during drought stress, which causes net ecosystem $\mathrm{C}$ uptake to decline relatively more (Schwalm et al., 2009; Ruehr et al., 2012), was captured by the modified model. Generally, during drought the ratio of respiration to photosynthesis may increase (Flexas et al., 2006). Measurements of nighttime needle respiration in ponderosa pine showed a $50 \%$ decrease in respiration compared to a $80 \%$ reduction in net photosynthesis by early September 2011 (data not shown). Accordingly, SPA was able to predict Ra to reduce less than GPP in response to the drought (compare $40 \%$ reduction of Ra to $60 \%$ reduction of GPP by September 2011). This supports our relatively simple way of modeling Ra from constant $\mathrm{C}$ allocation to the Ra pool with monthly turnover and a temperature dependency of respiration.

The mismatch between observed and modeled tree responses to the experimental water additions was caused by a shortcoming of the field experiment. The watered trees 


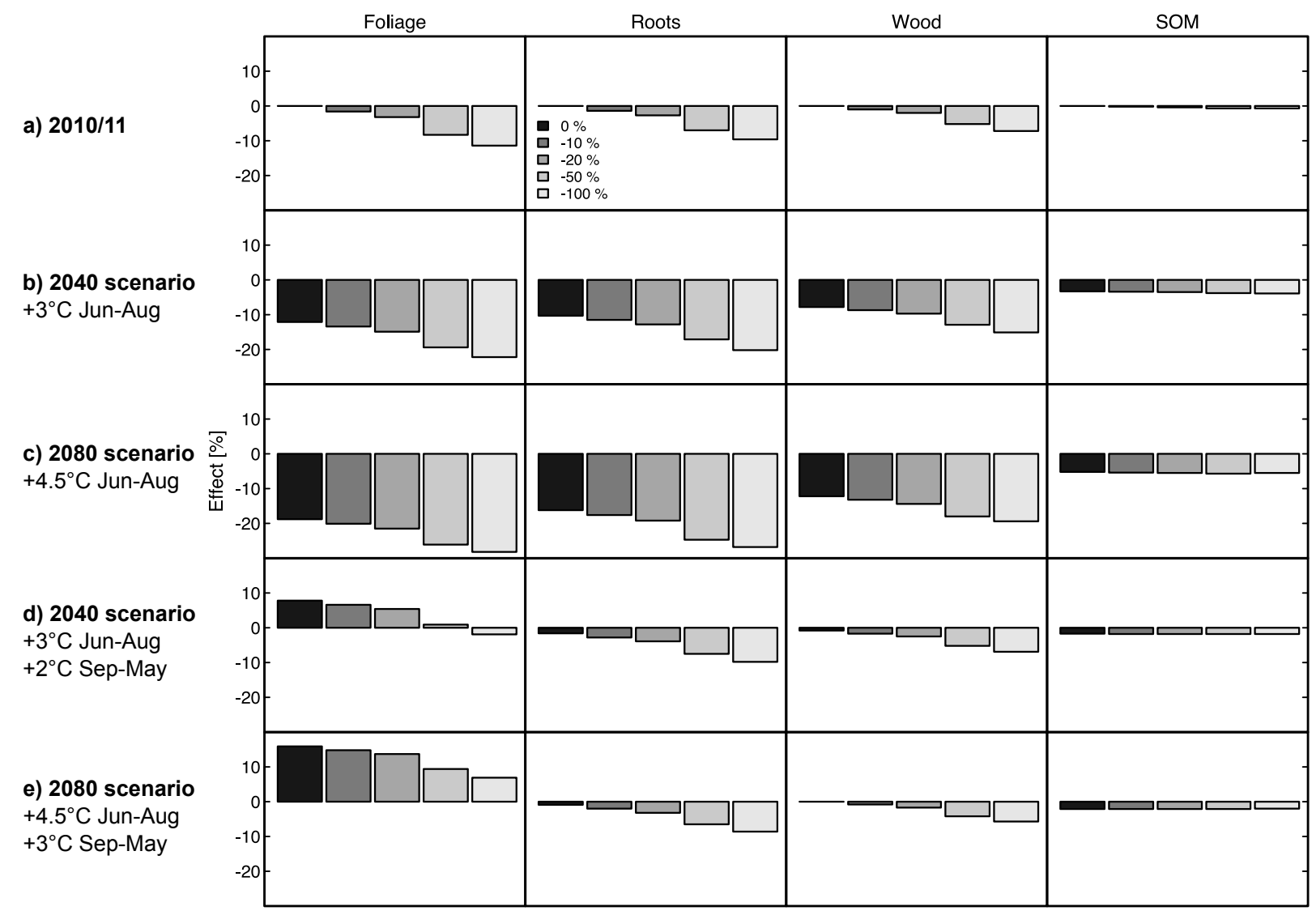

Figure 6. Effects of reduced precipitation and increased temperatures on simulated biomass and soil organic matter (SOM). percent mean annual changes of the $10 \mathrm{yr}$ model runs relative to the $2010 / 11$ control conditions ( $0 \%$ rain reduction) are given. Precipitation from June to August was decreased by 0,10,20,50 and 100\% (10 and 20\% reductions are in accordance with the climate scenarios for 2040 and 2080). 2010/11 temperature (a), only summer temperature increased (b) and (c), all-seasons temperature increased (d) and (e). Note that $\mathrm{CO}_{2}$ concentrations were 390 ppm for all scenarios.

experienced mild water limitation (about $40 \%$ loss in tree conductivity), while soil water content was close to field capacity. This was likely caused by the trees rooting partially outside the watered area, and thus some of the rooting system was exposed to dry soil. In controlled split-root experiments, even though part of a root system is well watered, it is not uncommon to observe drought stress-related decreases in stomatal conductance (e.g., Sobeih et al., 2004).

Interestingly, with water additions of $<200 \mathrm{~mm}$ the model confirms the overall experimental result. Increased water availability (while atmospheric conditions are unchanged) can result in a reduction of net ecosystem $\mathrm{C}$ uptake due to a larger increase in $\mathrm{Rh}$ than photosynthesis (see Ruehr et al., 2012). This clearly demonstrates that our modified SPA model was able to predict the experimental result of decomposition being tightly soil-moisture-limited during summer drought conditions.

\subsection{Temperature vs. precipitation effects}

The severity of droughts depends on both the amount of water available and temperature affecting atmospheric water deficit. Ranking their relative control over plant physiological processes is challenging as summer droughts are generally characterized by declining soil water content and a temperature dominated increase in atmospheric vapor pressure deficit (De Boeck and Verbeeck, 2011). Watering trees to maintain SWC close to field capacity during seasonal summer droughts provided us with the opportunity to study the effects of soil water limitation on the pines' physiology in more detail, and further allowed us to evaluate the effects of eliminated soil drought predicted by the SPA model. Changes in summer water availability had a pronounced effect on tree hydraulics; without irrigation, tree conductivity declined quickly, with a $80 \%$ loss in conductivity (compare to $40 \%$ in the watered treatment). This strong decline is in agreement with root conductivity measurements in young ponderosa pine during a summer dry season, which was linearly 


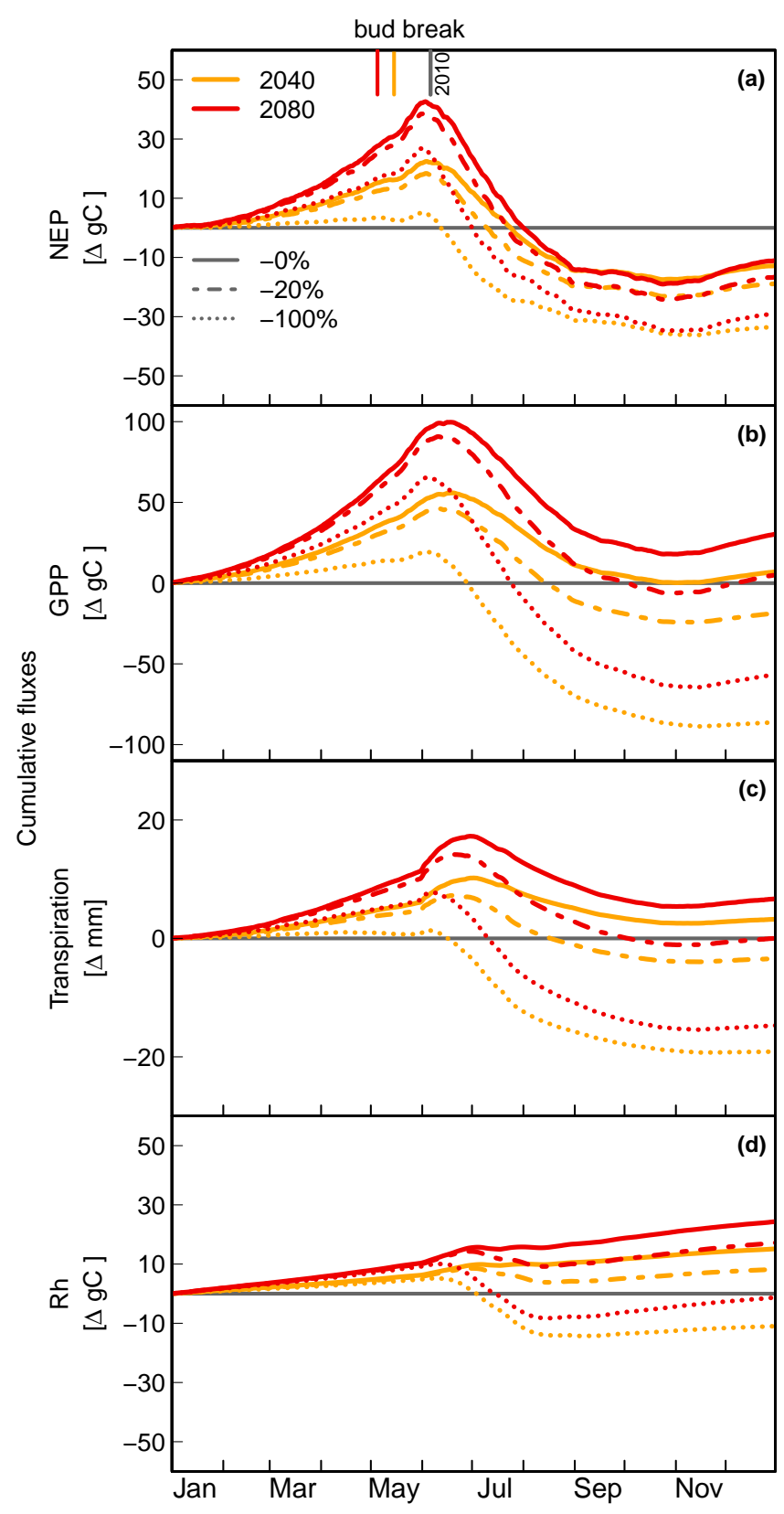

Figure 7. Seasonal course of anomalies in cumulative fluxes under future climate scenarios vs. 2010/11 conditions. Future scenarios are 2040 (June-Aug: $+3{ }^{\circ} \mathrm{C}$, September-May: $+2^{\circ} \mathrm{C}$ ) and 2080 (June-August: $+4.5^{\circ} \mathrm{C}$, September-May: $+3{ }^{\circ} \mathrm{C}$ ) with $0 \%, 20 \%$ or $100 \%$ rain reduction during summer. The timing of bud break under the 2010/11, 2040 and 2080 simulations are depicted by the vertical lines. Note that $\mathrm{CO}_{2}$ concentrations were $390 \mathrm{ppm}$ for all scenarios.

related to decreases in stomatal conductance (Domec et al., 2004). In addition to the limiting effects of soil drying, our observations showed a clear response of stomatal conductance to changes in VPD, superimposed on tree-water relations. The limiting effect of VPD was further confirmed by simulating the irrigation experiment using SPA. Despite non-limiting soil water conditions and large transpiration rates, GPP continued to decline. In contrast, when driving the model under low VPD conditions, stomatal conductance increased and largely maintained GPP rates close to predrought levels. This close regulation of water loss in young pine also became apparent during the onset of the summer dry season, when transpiration continued to increase due to large evaporative demand, while stomatal conductance decreased instantaneously causing GPP to decline (Ruehr et al., 2012). In the same study, we found a threshold for minimum daytime stomatal conductance at VPD of about $3.5 \mathrm{kPa}$, relatively independent of soil water content. This isohydric behavior of stomatal control has often been observed in pines (Martinez-Vilalta et al., 2004; Maseyk et al., 2008). To prevent further xylem embolisms, stomata partially close to maintain relatively constant midday leaf water potentials regardless of soil water availability (Domec et al., 2004; McDowell et al., 2008).

The tight regulation of water loss in pines explains the strong decline of photosynthesis with increasing summer temperatures (2040 and 2080 scenarios). Temperature has been confirmed to be an important driver of drought stress in US forests by exponentially increasing evaporative demand (Williams et al., 2013). In our study, summer temperatures as predicted for $2080\left(+4.5^{\circ} \mathrm{C}\right)$ caused a $40 \%$ increase in VPD that resulted in a similar decline of GPP and leaf biomass compared to the 2010/11 baseline. Extreme temperatures decreased transpiration due to tight stomata control and reduced biomass, but only slightly enhanced soil evaporation $(+3 \%)$, with the net effect on soil water content to be minimal $(<1 \%)$. Thus, increased temperatures and vapor pressure deficit causing stomata closure were the explanatory factors reducing GPP and biomass under future summer conditions. In summary, this largely confirms our first hypothesis that GPP in isohydric pine is affected more by changes in atmospheric demand than reductions in summer precipitation, but the degree depends on soil water status, influenced by drought severity and antecedent soil water content.

Hotter summer temperatures caused a much larger decline in net ecosystem $\mathrm{C}$ uptake than photosynthesis, due to minimal effects on Rh (Table 5). This was because temperature increases compensated for reductions in litter input and soil organic matter (see below). Thus this partially confirms our second hypothesis that GPP responded to increasing summer temperatures more than $\mathrm{Rh}$, while both were affected similar by declining summer precipitation.

\subsection{Effects of warmer and drier climate}

We concentrated our study on summer drought effects and temperature increases and did not account for elevated atmospheric $\mathrm{CO}_{2}$ in the simulation runs. Short-term effects of increased $\left[\mathrm{CO}_{2}\right]$ include stimulation of photosynthesis, reduced transpiration rates and changes in biomass allocation, while long-term effects can lead to acclimation processes 
Table 4. Effects of decreased drought compared to "normal" summer conditions derived from simulations with the SPA model. Shown are seasonal changes (June-September) in soil evaporation (E), transpiration (T), soil water storage ( $2 \mathrm{~m}$ soil depth) and drainage, as well as mean soil water content (0-40 cm soil depth). Seasonal treatment effects for gross primary productivity (GPP), net ecosystem productivity (NEP) and heterotrophic respiration $(\mathrm{Rh})$ are given. The annual treatment effects are given in brackets. The water addition treatments are shown in percent of water supplied to the irrigation experiment ( $\left(100_{\text {obs }}\right)$. The effects of reduced VPD are given for non-drought (w100_vpd1 $1_{\text {sim }}$ ) and normal summer drought conditions (ctrl_vpd $\left.1_{\text {sim }}\right)$.

\begin{tabular}{|c|c|c|c|c|c|c|c|c|c|c|}
\hline & Treatment & Water & $\mathrm{E}$ & $\begin{array}{l}\mathrm{T} \\
(\mathrm{mm})\end{array}$ & $\mathrm{W}_{\text {store }}$ & Drain & $\begin{array}{l}\mathrm{SWC}_{0-40} \\
\left(\mathrm{~m}^{3} \mathrm{~m}^{-3}\right)\end{array}$ & GPP & $\begin{array}{l}\mathrm{Rh} \\
(\%)\end{array}$ & NEP \\
\hline \multirow[t]{6}{*}{2010} & w30 sim & +131 & +121 & +3 & +6 & 0 & 0.13 & $+1(+1)$ & $+11(+5)$ & $-9(-4)$ \\
\hline & $\mathrm{w} 40_{\text {sim }}$ & +175 & +137 & +15 & +20 & 0 & 0.15 & $+7(+5)$ & $+20(+9)$ & $-1(-1)$ \\
\hline & $\mathrm{w} 50_{\text {sim }}$ & +218 & +149 & +25 & +42 & 0 & 0.18 & $+11(+7)$ & $+22(+10)$ & $+6(+3)$ \\
\hline & $\mathrm{w} 100_{\mathrm{sim}}$ & +436 & +162 & +39 & +87 & +145 & 0.21 & $+16(+9)$ & $+23(+10)$ & $+18(+10)$ \\
\hline & w100_vpd1 $1_{\text {sim }}$ & +436 & +153 & +45 & +85 & +151 & 0.21 & $+32(+18)$ & $+23(+11)$ & $+57(+32)$ \\
\hline & ctrl_vpd $1_{\text {sim }}$ & +0 & +0 & +4 & -3 & +0 & 0.21 & $+15(+8)$ & $-1(+0)$ & $+36(+21)$ \\
\hline \multirow[t]{6}{*}{2011} & w30 sim & +174 & +134 & +26 & +31 & 0 & 0.16 & $+12(+7)$ & $+32(+17)$ & $+3(-3)$ \\
\hline & w40 sim & +233 & +139 & +42 & +49 & 0 & 0.20 & $+17(+11)$ & $+33(+19)$ & $+15(+2)$ \\
\hline & $\mathrm{w} 50_{\operatorname{sim}}$ & +291 & +145 & +48 & +81 & +14 & 0.20 & $+19(+12)$ & $+34(+19)$ & $+20(+4)$ \\
\hline & $\mathrm{w} 100_{\mathrm{sim}}$ & +582 & +152 & +51 & +80 & +294 & 0.21 & $+20(+13)$ & $+34(+20)$ & $+24(+7)$ \\
\hline & w100_vpd1 sim $_{\text {sim }}$ & +582 & +148 & +66 & +78 & +284 & 0.21 & $+40(+26)$ & $+36(+22)$ & $+65(+32)$ \\
\hline & ctrl_vpd1 $1_{\text {sim }}$ & +0 & +0 & +3 & -5 & +0 & 0.21 & $+12(+8)$ & $-2(+0)$ & $+28(+18)$ \\
\hline
\end{tabular}

The annual treatment effect is given in brackets.

Table 5. Overview of the effects of climate scenarios on ecosystem fluxes in comparison to the 2010/11 conditions. The scenarios are: no summer precipitation, increased summer temperature and warming across all seasons (see Fig. 5). The larger effect between gross primary productivity (GPP) and heterotrophic respiration (Rh) is depicted in bold. Note that GPP is more affected by increases in summer temperature than by reductions in summer precipitation, confirming our first hypothesis. Considering our second hypothesis, we find a larger increase in $\mathrm{Rh}$ than GPP under the all-seasons warming scenario, while the change in summer precipitation affected Rh less than GPP.

\begin{tabular}{lllllll}
\hline & Scenarios & ET & T & $\begin{array}{l}\text { GPP } \\
(\%)\end{array}$ & Rh & NEP \\
\hline$-100 \%$ & summer precipitation & -15 & -12 & $\mathbf{- 9}$ & -10 & -8 \\
$+4.5^{\circ} \mathrm{C}$ & summer temperature & -3 & -9 & $-\mathbf{1 7}$ & -1 & -38 \\
$+3 / 4.5^{\circ} \mathrm{C}$ & all-seasons temperature* & +3 & +4 & +2 & $+\mathbf{+ 7}$ & -5 \\
\hline
\end{tabular}

* September-May: $+3^{\circ} \mathrm{C}$ and June-August $+4.5^{\circ} \mathrm{C}$.

and nitrogen limitation, causing down-regulation of photosynthetic activity and production (see review by Smith and Dukes, 2013). This down-regulation and decreased $\mathrm{CO}_{2}$ response has been shown to be stronger in low compared to high nutrient systems (Ainsworth and Long, 2005). In addition, experiments of plants grown under elevated $\left[\mathrm{CO}_{2}\right]$ indicate that growth benefits from water savings during seasonal droughts may be relatively small (Nowak et al., 2004; Perry et al., 2013). Thus, we can not exclude positive effects of elevated $\left[\mathrm{CO}_{2}\right]$ on GPP, but we speculate these responses to be relatively small in the seasonal dry, nutrient-poor ponderosa pine systems in central Oregon.

Increases in summer heat and drought severity reduced simulated NEP by 24 to $49 \%$ compared to the 2010/11 reference. This agrees with the effect of the turn-of-the-century drought (2000-2004) that led on average to a $37 \%$ reduction in net ecosystem $\mathrm{C}$ uptake of evergreen needleleaf forests in western North America (Schwalm et al., 2012). Partially confirming our second hypothesis, we found the strong reduction in modeled NEP to be caused by a larger decline in photosynthesis than heterotrophic respiration (Table 5). This pattern is commonly found in ecosystem studies and models (e.g., Shi et al., 2014, in this special issue), and can be largely explained by two processes that may act in concert. First, increasing temperatures during drought periods cause additional restrictions on GPP (see detailed explanation above), but may partially compensate for soil moisture constraints on decomposition (Irvine et al., 2008; Ruehr et al., 2012). Second, the response of decomposition may be buffered and lagged by large soil $\mathrm{C}$ pools and litter inputs downstream of GPP. Thus, if litter and soil C pools continue to decline, the initially large differences in Rh and GPP could also diminish over time (Shi et al., 2014). Interestingly, we found contrasting responses of decomposition rates and 
soil carbon pools in response to hotter summer temperatures. Large declines in GPP reduced litter production and soil organic matter decreased, but Rh was apparently relatively unaffected. A possible explanation is that increased temperatures largely compensated for reducing soil carbon pools by stimulating decomposition. However, one may speculate that the temperature-induced facilitation of decomposition dampens over the long term along with reductions in soil $\mathrm{C}$ pools.

Considering warming trends across all seasons, the complexity of ecosystem responses increased (Table 5). In semiarid ecosystems, the effects of earlier onset of spring growth are often complex and found to be partially offset by an earlier and longer duration of the summer drought period (Richardson et al., 2013). This was also predicted by SPA, despite large increases in early season GPP and a backward shift of maximum GPP by 9 days in the 2080 scenario, GPP declined more rapidly during the seasonal summer drought. Combined with the stimulation of $\mathrm{Rh}$ and adverse changes in above- and belowground biomass due to earlier bud break, the net $\mathrm{C}$ gain of the ecosystem decreased.

Bud break was predicted by SPA to occur up to 1 month earlier in 2080, causing a shift in the needle growth phenophase towards the more favorable growing conditions before the seasonal summer drought. Needle growth in Mediterranean pines has been described to occur largely during summer (Maseyk et al., 2008), supported by photosynthates gained during the growing season (Klein et al., 2005). Accordingly, needle growth in SPA directly depends on recent assimilates. Thus, needle biomass in the model increased due to $\mathrm{C}$ allocation to needle growth starting earlier. This also affected the amount of needle litter available by late summer which stimulated heterotrophic respiration. Moreover, increases in needle production affected allocation patterns causing an increase in the ratio of needle-to-root and needle-to-woody biomass. This is partly contradictory to a meta-analysis on the ratio of leaf to sapwood area in pines, where trees grown under a larger atmospheric water deficit showed a reduction in the ratio of leaf biomass to stem area (DeLucia et al., 2000). In agreement with this study, predictions of increased summer heat and drought scenarios by SPA resulted in a larger reduction in needle compared to root and woody biomass. Thus, positive effects on needle production only occurred in response to winter and spring warming. We can not further verify our findings, as to our knowledge there are no studies on the combined effects of warmer winter/spring temperatures and increased summer drought on pine phenology and $\mathrm{C}$ allocation patterns. Thus, these changes in biomass could be an artifact of the relatively simple allocation and phenology model we used. However, since needle growth in pine depends largely on current photosynthates and fine root growth in ponderosa pine shows a single peak of production at the end of May (Andersen et al., 2008), one could also argue that an earlier onset of needle growth may lead to a competition scenario between newly developing roots and needles. Such a shift in demand for current photosynthates may become a relevant threshold component for the pines' survival of drought stress over the long term. Thus, we speculate that more favorable early season growing conditions will not facilitate trees' survival of extreme stress, but that the imbalance of the needle-to-root biomass ratio as indicated in the simulation may increase the risk for hydraulic failure, ultimately leading to tree death (e.g., McDowell et al., 2013).

In summary, the model results largely confirmed our third hypothesis that an earlier start of the growing season could potentially compensate for the negative effects of more extreme summer droughts. But they also highlight that the longterm net effect may depend on the degree of heterotrophic respiration responding, and on the sensitivity of tree water and nutrient supply to changes in allocation patterns.

\section{Conclusions}

The calibrated soil-plant-atmosphere model was successfully validated against measurements from a regenerating semi-arid pine forest. To estimate the effects of soil and atmospheric drought, we applied a field watering experiment and simulated water additions as well as reduced atmospheric drought using the SPA model. The results from the field study and the simulation showed that soil water limitation has a pronounced effect on GPP, which was about similar in magnitude to VPD limitations during the summers of 2010 and 2011.

Accordingly, we found the decline in simulated GPP and biomass in response to hotter summers to nearly double the effect of reduced precipitation. The larger decline in NEP than GPP in response to future summer temperatures was caused by heterotrophic respiration being apparently unaffected by summer heat, while soil organic matter decreased. This effect might dampen over the long term with decreasing litter inputs along with reductions in soil $\mathrm{C}$ pools.

All-season warming largely mitigated most negative drought effects because of increased early season GPP and earlier bud break. In turn, this changed allocation patterns causing needle production to increase, while root productivity declined. The predicted imbalance in aboveground-tobelowground biomass may accelerate water stress over the long term to a threshold at which ponderosa pine may not survive. This highlights that, in order to quantify future effects of increasing drought severity, an integrated understanding of ecosystem processes responding to the combination of trends and extremes is needed.

The Supplement related to this article is available online at doi:10.5194/bg-11-4139-2014-supplement. 
Acknowledgements. This research was supported by a Leopoldina Research Fellowship from the German Academy of Sciences to NKR (LPDS 2009-37) and the Office of Science (BER), US Department of Energy (Award DE SC0005322). We like to thank the Oregon Department of Forestry in Sisters for their great support, K. Davis for maintaining the flux tower and C. Thomas and D. Vickers for flux tower data processing. We are also thankful to G. Xenakis for help with the SPA model and to K. McCulloh and J. C. Domec for discussions on tree-water transport and hydraulics, as well as to N. Buchmann and A. Ackermann for isotope analysis of water samples. We acknowledge support by Deutsche Forschungsgemeinschaft and the Open Access Publishing Fund of Karlsruhe Institute of Technology.

The service charges for this open access publication have been covered by a Research Centre of the Helmholtz Association.

Edited by: C. A. Williams

\section{References}

Ainsworth, E. A. and Long, S. P.: What have we learned from 15 years of free-air $\mathrm{CO}_{2}$ enrichment (FACE)? A meta-analytic review of the responses of photosynthesis, canopy properties and plant production to rising $\mathrm{CO}_{2}$, New Phytol., 165, 351-372, doi:10.1111/j.1469-8137.2004.01224.x, 2005.

Andersen, C. P., Phillips, D. L., Rygiewicz, P. T., and Storm, M. J.: Fine root growth and mortality in different-aged ponderosa pine stands, Can. J. Forest Res., 38, 1797-1806, doi:10.1139/X08029, 2008

De Boeck, H. J. and Verbeeck, H.: Drought-associated changes in climate and their relevance for ecosystem experiments and models, Biogeosciences, 8, 1121-1130, doi:10.5194/bg-8-11212011, 2011.

DeLucia, E., Maherali, H., and Carey, E.: Climate-driven changes in biomass allocation in pines, Glob. Change Biol., 6, 587-593, doi:10.1046/j.1365-2486.2000.00338.x, 2000.

Domec, J., Warren, J., Meinzer, F., Brooks, J., and Coulombe, R.: Native root xylem embolism and stomatal closure in stands of Douglas-fir and ponderosa pine: mitigation by hydraulic redistribution, Oecologia, 141, 7-16, doi:10.1007/s00442-004-1621-4, 2004.

Domec, J.-C., King, J. S., Noormets, A., Treasure, E., Gavazzi, M. J., Sun, G., and McNulty, S. G.: Hydraulic redistribution of soil water by roots affects whole-stand evapotranspiration and net ecosystem carbon exchange, New Phytol., 187, 171-183, 2010.

Easterling, D. R., Wallis, T. W. R., Lawrimore, J. H., and Heim, Richard R., J.: Effects of temperature and precipitation trends on US drought, Geophys. Res. Lett., 34, L20709, doi:10.1029/2007GL031541, 2007.

Fisher, R. A., Williams, M., Da Costa, A. L., Malhi, Y., Da Costa, R. F., Almeida, S., and Meir, P.: The response of an Eastern Amazonian rain forest to drought stress: results and modelling analyses from a throughfall exclusion experiment, Glob. Change Biol., 13, 2361-2378, doi:10.1111/j.1365-2486.2007.01417.x, 2007.

Flexas, J., Bota, J., Galmes, J., Medrano, H., and Ribas-Carbó, M.: Keeping a positive carbon balance under adverse conditions: re- sponses of photosynthesis and respiration to water stress, Physiol. Plantarum, 127, 343-352, 2006.

Gu, L., Pallardy, S. G., Tu, K., Law, B. E., and Wullschleger, S. D.: Reliable estimation of biochemical parameters from C-3 leaf photosynthesis-intercellular carbon dioxide response curves, Plant Cell Environ., 33, 1852-1874, doi:10.1111/j.13653040.2010.02192.x, 2010.

Hannerz, M.: Evaluation of temperature models for predicting bud burst in Norway spruce, Can. J. Forest Res., 29, 9-19, 1999.

Hanson, P. and Weltzin, J.: Drought disturbance from climate change: response of United States forests, Sci. Total Environ., 262, 205-220, 2000.

Hudiburg, T. W., Law, B. E., and Thornton, P. E.: Evaluation and improvement of the Community Land Model (CLM4) in Oregon forests, Biogeosciences, 10, 453-470, doi:10.5194/bg-10453-2013, 2013

Irvine, J., Law, B., Kurpius, M., Anthoni, P., Moore, D., and Schwarz, P.: Age-related changes in ecosystem structure and function and effects on water and carbon exchange in ponderosa pine, Tree Physiol., 24, 753-763, 2004.

Irvine, J., Law, B. E., Martin, J. G., and Vickers, D.: Interannual variation in soil $\mathrm{CO}_{2}$ efflux and the response of root respiration to climate and canopy gas exchange in mature ponderosa pine, Glob. Change Biol., 14, 2848-2859, 2008.

Kelliher, F., Ross, D., Law, B., Baldocchi, D., and Rodda, N.: Limitations to carbon mineralization in litter and mineral soil of young and old ponderosa pine forests, Forest Ecol. Manage., 191, 201-213, 2004.

Klein, T., Hemming, D., Lin, T., Grunzweig, J., Maseyk, K., Rotenberg, E., and Yakir, D.: Association between tree-ring and needle delta C-13 and leaf gas exchange in Pinus halepensis under semiarid conditions, Oecologia, 144, 45-54, doi:10.1007/s00442005-0002-y, 2005.

Law, B., Cescatti, A., and Baldocchi, D.: Leaf area distribution and radiative transfer in open-canopy forests: implications for mass and energy exchange, Tree Physiol., 21, 777-787, 2001.

Martinez-Vilalta, J., Sala, A., and Pinol, J.: The hydraulic architecture of Pinaceae - a review, Plant Ecol., 171, 3-13, 2004.

Maseyk, K. S., Lin, T., Rotenberg, E., Gruenzweig, J. M., Schwartz, A., and Yakir, D.: Physiology-phenology interactions in a productive semi-arid pine forest, New Phytol., 178, 603-616, doi:10.1111/j.1469-8137.2008.02391.x, 2008.

McDowell, N., Pockman, W. T., Allen, C. D., Breshears, D. D., Cobb, N., Kolb, T., Plaut, J., Sperry, J., West, A., Williams, D. G., and Yepez, E. A.: Mechanisms of plant survival and mortality during drought: why do some plants survive while others succumb to drought?, New Phytol., 178, 719-739, doi:10.1111/j.1469-8137.2008.02436.x, 2008.

McDowell, N. G., Fisher, R. A., Xu, C., Domec, J. C., Hölttä, T., Mackay, D. S., Sperry, J. S., Boutz, A., Dickman, L., Gehres, N., Limousin, J. M., Macalady, A., Martínez-Vilalta, J., Mencuccini, M., Plaut, J. A., Ogée, J., Pangle, R. E., Rasse, D. P., Ryan, M. G., Sevanto, S., Waring, R. H., Williams, A. P., Yepez, E. A., and Pockman, W. T.: Evaluating theories of drought-induced vegetation mortality using a multimodel-experiment framework, New Phytol., 200, 304-321, doi:10.1111/nph.12465, 2013.

Misson, L., Tu, K., Boniello, R., and Goldstein, A.: Seasonality of photosynthetic parameters in a multi-specific and vertically com- 
plex forest ecosystem in the Sierra Nevada of California, Tree Physiol., 26, 729-741, 2006.

Moldrup, P., Olesen, T., Komatsu, T., Schjonning, P., and Rolston, D.: Tortuosity, diffusivity, and permeability in the soil liquid and gaseous phases, Soil Sci. Soc. Am. J., 65, 613-623, 2001.

Mote, P., Bethel, J., Capalbo, S., Dalton, M., Eigenbrode, S., Glick, P., Houston, L., Littell, J., Lynn, K., Raymondi, R., Reeder, W., and Snover, A.: Climate Change in the Northwest, Brief Summary, 2013.

Nowak, R. S., Ellsworth, D. S., and Smith, S. D.: Functional responses of plants to elevated atmospheric $\mathrm{CO}_{2-}$ do photosynthetic and productivity data from FACE experiments support early predictions?, New Phytol., 162, 253-280, doi:10.1111/j.1469-8137.2004.01033.x, 2004.

Perry, L. G., Shafroth, P. B., Blumenthal, D. M., Morgan, J. A., and LeCain, D. R.: Elevated $\mathrm{CO}_{2}$ does not offset greater water stress predicted under climate change for native and exotic riparian plants, New Phytol., 197, 532-543, doi:10.1111/nph.12030, 2013.

Pierce, J., Meyer, G., and Jull, A.: Fire-induced erosion and millennialscale climate change in northern ponderosa pine forests, Nature, 432, 87-90, 2004.

R Development Core Team: R: A Language and Environment for Statistical Computing, R Foundation for Statistical Computing, Vienna, Austria, ISBN 3-900051-07-0, 2010.

Raz-Yaseef, N., Rotenberg, E., and Yakir, D.: Effects of spatial variations in soil evaporation caused by tree shading on water flux partitioning in a semi-arid pine forest, Agr. Forest Meteorol., 150, 454-462, 2010.

Richardson, A. D., Keenan, T. F., Migliavacca, M., Ryu, Y., Sonnentag, O., and Toomey, M.: Climate change, phenology, and phenological control of vegetation feedbacks to the climate system, Agr. Forest Meteorol., 169, 156-173, doi:10.1016/j.agrformet.2012.09.012, 2013.

Ruehr, N. K. and Buchmann, N.: Soil respiration fluxes in a temperate mixed forest: seasonality and temperature sensitivities differ among microbial and root-rhizosphere respiration, Tree Physiol., 30, 165-176, doi:10.1093/treephys/tpp106, 2010.

Ruehr, N. K., Martin, J. G., and Law, B. E.: Effects of water availability on carbon and water exchange in a young ponderosa pine forest: Above- and belowground responses, Agr. Forest Meteorol., 164, 136-148, doi:10.1016/j.agrformet.2012.05.015, 2012.

Schwalm, C. R., Williams, C., Schaefer, K., Arneth, A., Bonal, D., Buchmann, N., Chen, J., Law, B. E., Lindroth, A., Luyssaert, S., Reichstein, M., and Richardson, A. D.: Assimilation exceeds respiration sensitivity to drought: A FLUXNET synthesis, Glob. Change Biol., 16, 657-670, 2009.

Schwalm, C. R., Williams, C. A., Schaefer, K., Baldocchi, D., Black, T. A., Goldstein, A. H., Law, B. E., Oechel, W. C., Paw U, K. T., and Scott, R. L.: Reduction in carbon uptake during turn of the century drought in western North America, Nat. Geosci., 5, 551-556, 2012.

Schwarz, P., Law, B., Williams, M., Irvine, J., Kurpius, M., and Moore, D.: Climatic versus biotic constraints on carbon and water fluxes in seasonally drought-affected ponderosa pine ecosystems, Global Biogeochem. Cy., 18, GB4007, doi:10.1029/2004GB002234, 2004.
Shi, Z., Thomey, M. L., Mowll, W., Litvak, M., Brunsell, N. A., Collins, S. L., Pockman, W. T., Smith, M. D., Knapp, A. K., and Luo, Y.: Differential effects of extreme drought on production and respiration: synthesis and modeling analysis, Biogeosciences, 11, 621-633, doi:10.5194/bg-11-621-2014, 2014.

Smith, N. G. and Dukes, J. S.: Plant respiration and photosynthesis in global-scale models: incorporating acclimation to temperature and $\mathrm{CO}_{2}$, Glob. Change Biol., 19, 45-63, doi:10.1111/j.13652486.2012.02797.x, 2013.

Sobeih, W. Y., Dodd, I. C., Bacon, M. A., Grierson, D., and Davies, W. J.: Long-distance signals regulating stomatal conductance and leaf growth in tomato (Lycopersicon esculentum) plants subjected to partial root-zone drying, J. Exp. Bot., 55, 2353-2363, doi:10.1093/jxb/erh204, 2004.

Sus, O., Williams, M., Bernhofer, C., Beziat, P., Buchmann, N., Ceschia, E., Doherty, R., Eugster, W., Gruenwald, T., Kutsch, W., Smith, P., and Wattenbach, M.: A linked carbon cycle and crop developmental model: Description and evaluation against measurements of carbon fluxes and carbon stocks at several European agricultural sites, Agr. Ecosyst. Environ., 139, 402-418, doi:10.1016/j.agee.2010.06.012, 2010.

Vickers, D., Thomas, C. K., Pettijohn, C., Martin, J. G., and Law, B. E.: Five years of carbon fluxes and inherent water-use efficiency at two semi-arid pine forests with different disturbance histories, Tellus B, 64, 17159, doi:10.3402/tellusb.v64i0.17159, 2012.

Williams, A. P., Allen, C. D., Macalady, A. K., Griffin, D., Woodhouse, C. A., Meko, D. M., Swetnam, T. W., Rauscher, S. A., Seager, R., Grissino-Mayer, H. D., Dean, J. S., Cook, E. R., Gangodagamage, C., Cai, M., and McDowell, N. G.: Temperature as a potent driver of regional forest drought stress and tree mortality, Nat. Clim. Change, 3, 292-297, doi:10.1038/NCLIMATE1693, 2013.

Williams, M., Rastetter, E., Fernandes, D., Goulden, M., Wofsy, S., Shaver, G., Melillo, J., Munger, J., Fan, S., and Nadelhoffer, K.: Modelling the soil-plant-atmosphere continuum in a Quercus-Acer stand at Harvard forest: The regulation of stomatal conductance by light, nitrogen and soil/plant hydraulic properties, Plant Cell Environ., 19, 911-927, doi:10.1111/j.13653040.1996.tb00456.x, 1996.

Williams, M., Law, B., Anthoni, P., and Unsworth, M.: Use of a simulation model and ecosystem flux data to examine carbonwater interactions in ponderosa pine, Tree Physiol., 21, 287-298, 2001.

Williams, M., Schwarz, P., Law, B., Irvine, J., and Kurpius, M.: An improved analysis of forest carbon dynamics using data assimilation, Glob. Change Biol., 11, 89-105, 2005.

Wright, J. K., Williams, M., Starr, G., McGee, J., and Mitchell, R. J.: Measured and modelled leaf and stand-scale productivity across a soil moisture gradient and a severe drought, Plant Cell Environ., 36, 467-483, doi:10.1111/j.1365-3040.2012.02590.x, 2013.

Zeppel, M., Macinnis-Ng, C., Palmer, A., Taylor, D., Whitley, R., Fuentes, S., Yunusa, I., Williams, M., and Eamus, D.: An analysis of the sensitivity of sap flux to soil and plant variables assessed for an Australian woodland using a soil-plant-atmosphere model, Funct. Plant Biol., 35, 509-520, doi:10.1071/FP08114, 2008. 